$\underline{\text { Fátima Ramallo López }}$

\title{
La participación de las Entidades Locales en el Sistema para la Autonomía y la Atención a la Dependencia
}

SUMARIO: 1. INTRODUCCIÓN. 2. BREVE RECORRIDO POR LA LEY 39/2006, DE 14 DE DICIEMBRE, DE PROMOCIÓN DE LA AUTONOMÍA PERSONAL Y ATENCIÓN A LAS PERSONAS EN SITUACIÓN DE DEPENDENCIA. 2.1. Principios de aCtuación administrativa a favor DE la aUtonomía PERSONal. 2.2. Características básicas del Sistema para la Autonomía y Atención a la Dependencia. 2.3. Los mecanismos de cooperación: ¿Una apuesta por la DESCENTRALIZACIÓN DE LA GESTIÓN? 3. LA INCORPORACIÓN DEL CONCEPTO DE CIUDADANÍA A LAS NUEVAS POLÍTICAS DE ATENCIÓN A LAS PERSONAS EN SITUACIÓN DE DEPENDENCIA. 3.1. LA IMPORTANCIA DEL RECONOCIMIENTO DE LOS DERECHOS DE CIUDADANÍA PARA LOS GOBIERNOS LOCALES. 3.2. LA DEPENDENCIA EN LA DISTRIBUCiÓN DE COMPETENCIAS: El REPARTO DE PAPELeS en el Estado Autonómico. 3.2.a) Las competencias Estatales. 3.2.b) Las competencias de las Comunidades Autónomas. 3.2.c) Las competencias de los entes locales en la materia. 4. CONSIDERACIONES FINALES.

\section{INTRODUCCIÓN}

La Ley 39/2006 de Promoción de la autonomía personal y atención a las personas en situación de dependencia, en vigor desde el 1 de enero de 2007,

\footnotetext{
${ }^{1}$ Profesora de Derecho Administrativo, Universidad de Granada.
} 
representa otro de los logros alcanzados tras un largo proceso emprendido, en gran medida por los mismos beneficiarios de la misma y de las organizaciones representativas de sus derechos; y que culminó en 2003 con la aprobación de la Ley de igualdad de oportunidades, no discriminación y accesibilidad universal de las personas con discapacidad (LIONDAU) ${ }^{2}$.

Ahora, la Ley de la Dependencia viene a complementar el entramado normativo desarrollado en los últimos años, e iniciado con la LIONDAU a fin de crear un marco de referencia único para todas las Comunidades $\mathrm{Au}$ tónomas, tratando de evitar así la discriminación por razón de residencia. Y donde se contemple de forma integral el tratamiento y atención que ha de recibir las personas con discapacidad y en situación de dependencia por parte de las Administraciones públicas. Pero todo esto ahora se está realizando desde una perspectiva nueva, dejando a un lado el tradicional modelo de intervención pública meramente asistencial por uno que aborde de forma integral la problemática. Actuando a través de los servicios sociales y asistenciales, pero en conjunción con otras modificaciones y adaptaciones sociales que son consideradas necesarias a los fines de alcanzar la participación plena de las personas dependientes en la totalidad de las áreas de la vida social ${ }^{3}$.

Si bien ya han sido suficientemente analizados, en trabajos anteriores de este número de DA, los objetivos, los principios fundamentales que inspiran la Ley así con el funcionamiento del Sistema para la Autonomía y Atención a la Dependencia (SAAD) en el ámbito de la Administración General del Estado en colaboración con las diferentes Comunidades Autónomas. Es preciso comenzar este trabajo con un breve comentario a lo preceptuado en la misma,

2 Aquella Ley 52/2003 supuso un gran cambio en la forma de abordar la discapacidad desde el ámbito jurídico, ya que por primera vez se pasa de una concepción médica y de un modelo de intervención asistencia, de atención sanitaria y de seguridad social, o como parte de ciertas cuestiones del derecho civil relacionadas con la incapacitación y la tutela; a una concepción social del fenómeno y a un modelo que sitúa el centro de atención en la sociedad. Según los defensores del modelo social, no son las limitaciones individuales las causas del problema, sino las limitaciones de la sociedad para prestar servicios apropiados y para asegurar adecuadamente que las necesidades de las personas con discapacidad sean tenidas en cuenta dentro de la organización social. Ahora se plantea el fenómeno como una cuestión de derechos humanos. Este modelo de intervención pública considera a la discapacidad como un problema de origen social, en el que la misma no es simplemente un atributo de la persona, sino un complejo conjunto de condiciones, muchas de las cuales son creadas por el contexto social, y en este ámbito es en el que hay que intervenir para lograr la integración plena en la vida social del país de las personas con discapacidad. Para profundizar en esta cuestión es de interés consultar la obra de VALDÉs "Derechos en serio y personas con discapacidad: una sociedad para todos", en Relaciones Laborales de las personas con discapacidad, Biblioteca Nueva, Editado por Fundación Largo Caballero, Fundación ONCE y Fundación Ortega y Gasset, Madrid, 2005.

${ }^{3}$ Véase nota al pie 1. 
con la idea de exponer los elementos del enfoque sistémico y de las interrelaciones administrativas que su puesta en práctica ha de tener en cuenta para el éxito de la política planteada en esta norma. Para ello trataremos en primer lugar las características y principios de la Ley para finalizar por el déficit competencial que las entidades locales están padeciendo en esta materia.

Así, el objetivo primordial de este trabajo es tomar esta Ley y su filosofía, como punto de partida para dar cuenta de la necesidad de llevar a cabo, definitivamente, la articulación de un marco de colaboración interadministrativa que ponga los intereses y los derechos reconocidos de los beneficiarios de esta norma por encima de los intereses políticos, garantizando así la efectividad de las prestaciones en ella reconocidas; y que la autonomía de las personas sea, de una vez por todas, una realidad tangible en nuestro Estado de Bienestar ${ }^{4}$.

\section{BREVE RECORRIDO POR LA LEY 39/2006, DE 14 DE DICIEMBRE, DE PROMOCIÓN DE LA AUTONOMÍA PERSONAL Y ATENCIÓN A LAS PERSONAS EN SITUACIÓN DE DEPENDENCIA}

En concreto, la norma que nos ocupa, va dirigida a cubrir las necesidades de personas que por su avanzada edad o por su nivel de discapacidad, necesitan del apoyo de otras personas para el desempeño tanto de las actividades básicas de la vida cotidiana (alimentarse, asearse, vestirse, etc.), como de aquellas otras funcionalidades necesarias para poder ejercer su ciudadanía en igualdad de condiciones que el resto de las personas, (participar en actividades culturales, recreativas y sociales, por ejemplo). En definitiva, que les proporcionen una mayor calidad de vida.

Así lo pone de manifiesto el artículo 1, donde se establece que esta Ley tiene por objeto "regular las condiciones básicas que garanticen la igualdad en el ejercicio del derecho subjetivo de ciudadanía a la promoción de la autonomía personal y atención a las personas en situación de dependencia...”

Para saber quiénes son los posibles beneficiarios del Sistema para Autonomía y Atención a la Dependencia que se regula en esta norma para hacer efectivo el "derecho subjetivo de ciudadanía" que reconoce, la Ley realiza una serie de definiciones esenciales para la comprensión de las finalidades y destinatarios del Sistema.

\footnotetext{
${ }^{4}$ En esta línea es de interés la consulta al trabajo de Tomás-Ramón Fernández "De la banalidad a la incoherencia y la arbitrariedad. Una crónica sobre el proceso, al parecer imparable, de degradación de la Ley", El cronista del Estado Social y Democrático de Derecho, Madrid, n. ${ }^{\circ} 0$, noviembre de 2008.
} 
En primer lugar define la dependencia, en el artículo 2, como "El estado de carácter permanente en que se encuentran las personas que, por razones derivadas de la edad, la enfermedad o la discapacidad, y ligadas a la falta o a la pérdida de autonomía física, mental, intelectual o sensorial, precisan de la atención de otra $\mathrm{u}$ otras personas o ayudas importantes para realizar actividades básicas de la vida diaria, o en el caso de las personas con discapacidad intelectual o enfermedad mental, de otros apoyos para su autonomía personal."

Igualmente, y con la misma filosofía, la Ley describe lo que ha de entenderse por actividades básicas de la vida diaria para acotar de alguna manera los ámbitos de las prestaciones y servicios que reconoce a las personas que se encuentran en situación de dependencia ${ }^{5}$. Así, se entiende como tales, "aquellas tareas más elementales de la persona, que le permiten desenvolverse con un mínimo de autonomía e independencia, como puede ser el cuidado personal, las actividades domésticas básicas, la movilidad esencial, reconocer personas y objetos, orientarse, entender y ejecutar órdenes o tareas sencillas". No obstante lo anterior, se trata de evitar una limitación a la aplicación de esta norma que sea negativa para el libre desarrollo de la personalidad de las personas con discapacidad o dependientes al añadir, en la definición de dependencia, la expresión "otros apoyos para su autonomía personal”. Lo que hace alusión a aquellas otras ayudas que requieren las personas que tienen algún tipo de discapacidad física, intelectual o mental, para hacer efectivo un grado satisfactorio de autonomía personal en el seno de la comunidad.

Se incorpora de esta forma una definición que se acerca aún más al reconocimiento de los derechos subjetivos de ciudadanía y a ese modelo social de intervención de que hablábamos en páginas anteriores, que a un modelo de atención social meramente asistencial o médico, lo que constituye el elemento de básico en el que apoyar la expansión de un auténtico sistema de promoción de la autonomía para las personas en situación de dependencia por todo el territorio español, que valla mas allá de las ayudas que se quedan en el estricto ámbito de desarrollo personal del individuo. Porque como veremos, realmente la filosofía de la Ley, pese a la sobriedad con que realiza algunas descripciones y ayudas, alcanza también al mandato que la Constitución puso a los poderes públicos en aras de facilitar la participación de todos los ciudadanos en la vida política, económica, cultural y social ${ }^{6}$. Ya que al reconocer un derecho subjetivo de ciudadanía en torno al cual se articula todo el sistema, está reconociendo la necesidad de articular medidas

${ }^{5}$ La situación de dependencia ha de ser valorada y reconocida por los órganos de valoración que designe la Comunidad Autónoma (artículo 27 de la Ley de Dependencia).

${ }^{6}$ Art. 9.2 de la Constitución Española. 
para que las personas que se integran en este colectivo se conviertan en ciudadanos de pleno derecho, y en todos los ámbitos de la vida ${ }^{7}$.

En el acceso a las prestaciones y servicios regulados en la Ley se prioriza a los grandes dependientes. Aunque con la idea de abarcar a todas las personas dependientes, se clasifica la situación de dependencia en diferentes grados: dependencia moderada, dependencia severa y gran dependencia ${ }^{8}$, lo que se valorará en función de criterios acordados en el respectivo baremo", y que será lo que determine la percepción de unos tipos de ayudas u otras. Igualmente, como correlato a la anterior clasificación se establecen tres niveles de protección. Un mínimo garantizado en gran medida por el Estado, y otros dos que dependerán de los acuerdos de colaboración que suscriban las Comunidades Autónomas con aquel, o con sus respectivas entidades locales y que sólo se harán efectivos en el momento en que se desarrollen los preceptos de la Ley en tal sentido.

Pero lo que es más importante en la materia que nos ocupa es que nos encontramos ante una ley que genera un derecho subjetivo de ciudadanía, un derecho de ciudadanía social. Esto supone que la persona dependiente, tiene como ciudadano, más allá del ejercicio de sus derechos civiles y políticos, el derecho social a su atención y promoción de su autonomía personal para el ejercicio de esos otros derechos que como ciudadano les corresponden.

Reconocimiento que, además, juega un papel esencial a la hora de determinar el rol de los gobiernos locales en el desarrollo y correcta aplicación y funcionamiento de los sistemas previstos en la Ley; pues de alguna manera legitima, por un lado, las reivindicaciones de los municipios que reclaman que sus ayuntamientos, la Administración más cercana al ciudadano, se instituyan como auténticos ejecutores de los servicios articulados en la Ley,

7 Otros principios que inspiran este modelo social tienen su origen en la LIONDAU, Ley $51 / 2003$, cuyo artículo 2 establece que las políticas de atención a la discapacidad y a las personas en situación de dependencia en España se han de inspirar en una serie de principios: estos son, vida independiente, normalización, accesibilidad universal, diseño para todos, diálogo civil y transversalidad de las políticas en materia de discapacidad.

${ }^{8}$ Las definiciones de estas tipologías de dependencia se determinan en la propia ley, lo que constituye una cuestión interesante, ya que al definir conceptos que pueden tener diferentes acepciones (como autonomía, dependencia, cuidados no profesionales, tercer sector, etc.) quedan incorporados como glosario legal, con un significado compartido.

9 Este baremo donde se establecen los criterios objetivos de valoración del grado de autonomía de la persona, de su capacidad para realizar las distintas actividades de la vida diaria, los intervalos de puntuación para cada uno de los grados y niveles de dependencia, y el protocolo con los procedimientos y técnicas a seguir para la valoración de las aptitudes observadas, en su caso; se acordó en el Consejo Territorial del Sistema para la Autonomía y Atención a la Dependencia, y fue aprobado posteriormente por el Gobierno mediante Real Decreto 504/2007, de 20 de abril de conformidad con el artículo 27 de la Ley de Dependencia. 
para así garantizar su eficiente aplicación y con criterios de igualdad en todo el territorio nacional. Y por otro, que en definitiva, el nivel de protección y atención personal reconocido en la Ley no se quede en el ese mínimo garantizado por el Estado, sino que vaya más allá y se concrete en la suscripción de los respectivos acuerdos de colaboración, que serán los instrumentos por los que todas las personas en situación de dependencia, si cumplen los requisitos legal o reglamentariamente previstos, puedan acceder a un elenco de ayudas y prestaciones cada vez mayores para su bienestar. $Y$ en definitiva, para el pleno ejercicio de sus derechos.

\subsection{Principios de aCtUaCión administrativa A FaVor DE LA AUTONOMÍA PERSONAL}

Los principios en que se inspira esta ley, se pueden clasificar en tres grupos. Aquellos que configuran la cartera de prestaciones recogida en la ley como un auténtico elenco de servicios públicos. Entre ellos se puede mencionar el carácter público de las mismas y la universalidad, la calidad, sostenibilidad y accesibilidad de los servicios de atención a las personas en situación de dependencia, y en condiciones de igualdad efectiva y no discriminación ${ }^{10}$.

Aquellos otros característicos de las políticas sociales y de promoción de la igualdad entre los que se encuentran la transversalidad de las políticas de atención a las personas situación de dependencia, encaminando así las actuaciones que desarrollan las Administraciones públicas hacia políticas y líneas de acción de carácter general y que incidan en cualquiera de los ámbitos de actuación pública, en donde se tendrán en cuenta las necesidades y demandas de las personas con discapacidad ${ }^{11}$. Junto con ello encontramos la

${ }_{10}$ Estos principios, recogidos en el artículo 3 de la Ley de Dependencia, se amplían con el apartado k) del artículo 4. -que regula los derechos y obligaciones de las personas en situación de dependencia- donde se establece el derecho a la igualdad de oportunidades, no discriminación y accesibilidad universal, en cualquiera de los ámbitos de desarrollo y aplicación de esta Ley. Derechos que derivan directamente del principio de accesibilidad universal recogido por primera vez en España en la Ley 51/2003 LIONDAU y cuyo significado se define en su artículo 2 a) como "la condición que deben cumplir los entornos, procesos, bienes, productos y servicios, asi como los objetos o instrumentos, herramientas y dispositivos, para ser comprensibles, utilizables $y$ practicables por todas las personas en condiciones de seguridad y comodidad y de la forma más autónoma y natural posible". Esta definición de accesibilidad universal presupone la estrategia de "diseño para todos" sobre la que ha escrito un interesante trabajo Fernández Gutiérrez, C.R.: "La igualdad de oportunidades, la no discriminación y la accesibilidad universal como ejes de una nueva política a favor de las personas con discapacidad”, Documentación social, núm. 130, Madrid. 2003, pp. 25-40.

${ }^{11}$ El mainstreaming o transversalidad es un concepto de reciente aparición en el marco de las políticas de igualdad de oportunidades en el contexto europeo. Sus orígenes se encuentran 
valoración de las necesidades de las personas, atendiendo a criterios de equidad para garantizar la igualdad real, la inclusión de la perspectiva de género, teniendo en cuenta las distintas necesidades de mujeres y hombres, y la plena participación social de las personas en situación de dependencia y, en su caso, de sus familias y entidades que les representen. Con esto último se incorpora el principio de diálogo civil con los principales interesados en el diseño de políticas públicas, quienes en definitiva, son los primeros conocedores de sus carencias y los mejores expertos en cuanto a sus necesidades concretas y a la eficacia de las potenciales soluciones.

Y por último, como complemento a estos principios que han de inspirar la actuación de los poderes públicos a favor de la autonomía personal de las personas en situación de dependencia encontramos los tradicionales principios de cooperación interadministrativa, y de colaboración de los servicios sociales y sanitarios; añadiéndose a ellos, como novedad, la participación de la iniciativa privada y del tercer sector en los servicios y prestaciones. Una forma de instar la coparticipación de diversos componentes de la estructura social que nos muestra el posicionamiento del Estado con respecto a la protección social de la población, donde éste asume un papel relevante interviniendo en ámbitos hasta hace poco considerados como "privados" o "domésticos", y compartiendo la gestión con el sector privado de servicios.

En tercer lugar, encontramos un conjunto de principios que enfocan la problemática de la dependencia como una cuestión de derechos humanos, lo que significa abordar de manera apropiada los valores que la sustentan, esto es la dignidad, libertad e igualdad. Para ello existe un elenco de principios que dejan claro cuál ha de ser el grado de bienestar que debe alcanzar la persona dependiente como sujeto de derechos humanos, como ciudadano de una sociedad compleja pero integradora. Entre ellos destacamos los siguientes:

- La personalización de la atención.

- El establecimiento de medidas adecuadas de prevención, rehabilitación, estímulo social y mental.

- La permanencia de las personas en situación de dependencia, siempre que sea posible, en el entorno en el que desarrollan su vida.

en las Conferencias Mundiales de las Mujeres de Naciones Unidas. Ya en la III Conferencia celebrada en Nairobi en 1985 se comienza a utilizar este término, pero realmente es abordado y desarrollado, y cobra una importancia relevante en el contexto de las políticas de igualdad de oportunidades en la VI Conferencia Mundial de las Mujeres celebrada en Pekín en 1995. Véase: Consejo de Europa, Grupo de Especialistas en Mainstreaming: Mainstreaming de género: marco conceptual, metodología y presentación de "buenas prácticas": Informe final de las actividades del Grupo de Especialistas en Mainstreaming (EG-S-MS), Estrasburgo, Madrid, 1999. 
- La atención preferencial a las personas en situación de gran dependencia.

- La atención a las personas en situación de dependencia de forma integral e integrada.

Es fácilmente perceptible, a través del análisis de estos principios, y otros más recogidos en la Ley que no quedan aquí plasmados, que detrás de esta norma subyace la filosofía del movimiento de vida independien$\mathrm{te}^{12}$, y una estrategia, por tanto, que supone mucho más que la incorporación de las políticas específicas en las políticas generales de transportes, salud, servicios sociales, empleo, juventud, turismo, etc., constituyendo una estrategia completa e integradora. Una estrategia que requiere un verdadero cambio y una reorganización a todos los niveles de gobierno, a fin de que las personas en situación de dependencia puedan contar con las condiciones necesarias capaces de dirigir sus propias vidas y de cuidar de ellas mismas ${ }^{13}$.

\subsection{Características básicas del Sistema para la Autonomía y Atención a la Dependencia}

Para el cumplimiento de los fines planteados y para la consecución plena de los principios enumerados, la Ley crea un Sistema para la Autonomía y Atención a la Dependencia (SAAD) de carácter socio-sanitario, para la atención y cuidado de personas mayores y dependientes. Este Sistema se ha configurado como una red de utilización pública que integra de forma coordinada, centros y servicios, públicos y privados.

${ }_{12}$ El Movimiento de Vida Independiente nació en Estados Unidos en la década del sesenta. La filosofía de vida independiente pretende cambiar el punto de vista que la sociedad tiene sobre las personas con discapacidad y, en especial, sobre las que requieren de la asistencia de otras personas para el desarrollo de su vida diaria. El lema "Nothing about us whithout us"-Nada sobre nosotros sin nosotros- que surgió con el modelo de vida independiente, resume de manera efectiva esta postura, que tiende a que se cuente con la participación del colectivo, solo así, se considera que se puede llegar a un sistema realmente "diseñado para todos". Véase sobre este concepto el interesante trabajo de Charton, J. I.: Nothing About Us Without Us: Disability Oppression and Empowerment, University of California Press, Berkeley, 1998. En nuestra legislación este movimiento se incorpora a través de la mencionada LIONDAU en sus principios inspiradores y que se mencionan en la nota al pie 5 .

${ }^{13}$ Así lo pone de manifiesto en párrafos segundo del apartado 3. ${ }^{\circ}$ de la Exposición de Motivos cuando dice ".....configura un derecho subjetivo que se fundamenta en los principios de universalidad, equidad y accesibilidad, desarrollando un modelo de atención integral al ciudadano, al que se reconoce como beneficiario su participación en el Sistema y que administrativamente se organiza en tres niveles..." 


\section{Las principales directrices de este Sistema son:}

- Proveer centros y servicios públicos de atención y cuidado a adultos mayores y personas dependientes.

- Regular desde el Estado centros y servicios privados de atención y cuidado a adultos mayores y otras personas dependientes.

- Eventualmente subsidiar a los adultos mayores posibilitándoles la contratación de cuidados domiciliarios o internación en residencias del sector privado de servicios, así como otorgar subsidios a los familiares que cuidan a miembros de su familia, afiliándolos al sistema de Seguridad Social.

- Profesionalizar la atención a personas dependientes, adultos mayores o discapacitados, capacitando a los cuidadores y sacando esta actividad del ámbito de la familia.

Como se puede detectar, se ha optado por proporcionar más prestaciones de servicios que prestaciones económicas ${ }^{14}$, aunque también se otorgan ayudas económicas vinculadas al servicio, que pueden consistir, por ejemplo, en subsidios al adulto mayor o persona en situación de dependencia por razón de la discapacidad, para que pueda acceder a servicios privados en ciertos casos; ayudas técnicas y de adaptabilidad de las viviendas, o subsidios para el familiar que cuida al adulto mayor u otra persona dependiente, siempre que se cumplan determinados requisitos legalmente establecidos, como son los de ajustarse a las normas sobre afiliación, alta y cotización a la Seguridad Social.

Asimismo se prevén otras ayudas económicas de asistencia personal, previstas para cubrir la necesidad para personas con gran dependencia, de contar con una persona que le asista para aseo personal, así como trasladarlo a centros de trabajo o de estudio ${ }^{15}$. En todos los casos los servicios se otorgan en función del grado y nivel de dependencia y de la capacidad económica del beneficiario.

${ }^{14}$ Cuestión que ha determinado que en el primer balance que se ha hecho de este Sistema se haya destacado que, como efecto asociado, ha provocado, la generación de empleo a través del sistema de seguridad social. De hecho, algunos de los principales datos aportados por la Secretaria de Estado de Política Social, Amparo Valcarce, a la hora de hacer balance del estado de aplicación de la Ley con fecha 1 de septiembre de 2008, se centran en que la Ley de Dependencia ha generado 70.000 empleos y ha reconocido a más de 346.000 personas como beneficiarios con derecho a prestación. A día de hoy existen 50.000 personas que prestan cuidados familiares en sus domicilios, de los cuales 24.000 cotizan a la Seguridad Social.

${ }^{15}$ Estas ayudas económicas se regulan en la Sección segunda del Capítulo 1 de la Ley de Dependencia, artículos 16 a 20. 


\section{La Cartera de Servicios}

Se evalúa el nivel de salud, las características de la dependencia, así como el entorno familiar y se abre un catálogo con carteras de servicios. Servicios que se prestan, en la actualidad, mediante centros y servicios públicos o privados concertados debidamente acreditados por las Comunidades Autónomas, así como a través de Organizaciones No Gubernamentales sin fines de lucro o entidades empresariales con fines de lucro ${ }^{16}$.

El catálogo de servicios comprende desde servicios de prevención de las situaciones de dependencia y los de orientación para la autonomía personal, para prevenir la aparición o el agravamiento de enfermedades o discapacidades y de sus secuelas, mediante el desarrollo coordinado entre los servicios sociales y de salud; hasta otros programas específicos que pueden ser de atención asistencial y personal, de rehabilitación o para promoción de la autonomía.

Entre estos, se destacan, por su novedad y carácter eminentemente local, los Servicios de Teleasistencia ${ }^{17}$, que facilitan asistencia a los beneficiarios mediante el uso de tecnologías de la comunicación y de la información, en respuesta inmediata ante situaciones de emergencia, o de inseguridad, soledad y aislamiento; y los servicios de Ayuda a domicilio para la atención de las necesidades del hogar u otros cuidados personales, junto con los servicios de Centro de Día y de Noche y otras Residencias que ofrecen una atención integral, con el objetivo de mejorar o mantener el mejor nivel posible de autonomía personal y apoyar a las familias o cuidadores ${ }^{18}$.

\subsection{LOS MECANISMOS DE COOPERACIÓN: ¿UNA APUESTA POR LA DESCENTRALIZACIÓN DE LA GESTIÓN?}

Se establece específicamente en la Exposición de Motivos de la ley que "La propia naturaleza y objeto de esta ley requiere un compromiso y una actuación

${ }^{16} \mathrm{Al}$ desarrollo de la prestación de dichos servicios están contribuyendo de una forma importante los servicios de atención social de la Cruz Roja y otras entidades que desarrollan programas asistenciales a través de la responsabilidad social corporativa que asumen sus socios en sus estatutos o en sus objetivos fundacionales.

${ }^{17}$ Este programa se instrumentó a través de un convenio-marco suscrito entre el Instituto de Mayores y Servicios Sociales (IMSERSO) y la Federación Española de Municipios y Provincias (FEMP) el día 20 de abril de 1993, al que han ido adhiriendo progresivamente a través de convenios específicos de colaboración las corporaciones locales interesadas en la implantación del programa en sus ámbitos territoriales respectivos. Actualmente se está actualizando su gestión en la mayoría de las Comunidades Autónomas mediante la aprobación de diversos instrumentos normativos en desarrollo de la Ley de Dependencia

18 Artículo 15 de la Ley de Dependencia. 
conjunta de todos los poderes e instituciones públicas, por lo que la coordinación y cooperación con las Comunidades Autónomas es un elemento fundamental. Para ello la ley establece una serie de mecanismos de cooperación...”.

En esta línea de actuación nace el Consejo Territorial del Sistema para la Autonomía y Atención a la Dependencia, constituido por el titular del Ministerio de Trabajo y Asuntos Sociales y por un representante de cada una de las Comunidades Autónomas, y por dos representantes de las entidades locales designados por la Federación Española de Municipios y Provincias ${ }^{19}$. Este Consejo se crea como un instrumento de cooperación para la articulación del Sistema, por tanto, es el órgano en el que se debe acordar el Marco de Cooperación Interadministrativa; el que establece los criterios para determinar la intensidad de protección de los servicios previstos; los criterios bajo los que se acuerdan las condiciones y cuantías de las prestaciones económicas, así como de otros criterios comunes de actuación y de evaluación del sistema. En síntesis, es un organismo que nace como un auténtico cauce de cooperación, comunicación e información entre las Administraciones públicas ${ }^{20}$.

Por otra parte, en cuanto a la participación de los diferentes niveles de Gobierno en la ejecución y sostenimiento del sistema, la Ley establece tres niveles de protección en función del grado de compromiso que asuman en la gestión del Sistema las diferentes entidades territoriales, y que se corresponderán con los grados de dependencia que hayan sido determinados por las autoridades competentes para ello. Así, en primer lugar, se determina un nivel mínimo de protección garantizado para cada uno de los beneficiarios del Sistema, según el grado y nivel de su dependencia, como condición básica de garantía del derecho a la promoción de la autonomía personal y atención a la situación de dependencia ${ }^{21}$. Un sistema en el que el Estado

19 También está prevista la constitución de un Comité Consultivo del SAAD cuya finalidad será hacer efectiva la participación institucional en el Sistema de las tres Administraciones públicas (Central, Autonómica y Local) así como de las organizaciones sindicales y empresariales. Será la FEMP quien designe a los representes locales en este Comité. Esté Comité llevará a cabo similares funciones y con la misma finalidad de garantizar la participación social en el Sistema de las entidades representativas de las personas en situación de dependencia y sus familias, son igualmente órganos consultivos de participación institucional del SAAD el Consejo Estatal de Personas Mayores, el Consejo Nacional de la Discapacidad, el Consejo Estatal de Organizaciones no Gubernamentales de Acción Social.

20 Véase el Artículo 8 de la Ley de Dependencia.

${ }^{21}$ Este nivel mínimo de protección del Sistema para la Autonomía y Atención a la Dependencia que le corresponde sufragar al Estado, lo determina el Gobierno, oído el Consejo Territorial del Sistema para la Autonomía y Atención a la Dependencia. De esta forma, el Gobierno aprobó por Real Decreto 614/2007, de 11 de mayo, con el objeto de establecer las cuantías para el nivel mínimo de protección garantizado por la Administración General del Estado para el ejercicio 2008, de acuerdo a lo previsto en el artículo 9 de la Ley de Dependencia, las cuales 
tiene la responsabilidad de definir y garantizar financieramente un nivel mínimo de protección ${ }^{22}$. Para que ese nivel mínimo se vea incrementado se plantea la coparticipación en la financiación de las Comunidades Autónomas y de los propios beneficiarios a través de diversas fórmulas como son los Convenios de colaboración que se pueden dar entre estos dos niveles territoriales de distribución del poder - el Estado y las Comunidades Autónomas- o entre las Comunidades Autónomas con sus corporaciones locales u otras corporaciones de derecho público o entidades privadas.

En definitiva, lo que esta norma prevé es un aumento de los niveles mínimos de protección que garantiza el Estado, en dos niveles, de llevarse a cabo escalonadamente y, en primer lugar a través de posibles Convenios de Colaboración articulados entre el Estado y las Comunidades Autónomas, en desarrollo del Marco de Cooperación Interadministrativa que se acuerde por el Consejo Territorial del Sistema para la Autonomía y Atención a la Dependencia ${ }^{23}$. Y adicionalmente prevé la posibilidad de que ese nivel acordado de protección pueda llegar más allá, mediante un nuevo Convenio de colaboración, llegando ya a un tercer nivel de descentralización territorial, que en este caso se llevaría a cabo con Acuerdos adoptados entre las Comunidades Autónomas y las entidades locales.

De la configuración de este Sistema cabe extraer dos conclusiones. Una, ya histórica en la búsqueda del papel que sitúe a los gobiernos locales como auténticos actores con autonomía política y administrativa en el desarrollo

\footnotetext{
se actualizarán anualmente según el calendario de aplicación progresiva establecido en la disposición adicional primera de la Ley de Dependencia. El nivel mínimo de protección de la situación de dependencia se garantiza mediante la fijación de una cantidad económica que la Administración General del Estado aporta a la financiación del Sistema por cada uno de los beneficiarios reconocidos como dependientes según su grado y nivel, para las prestaciones de dependencia previstas en su programa individual de atención. Pero estas cantidades no se satisfarán a las Comunidades Autónomas en cualquier caso, sino en función del número de beneficiarios reconocidos en situación de dependencia con derecho a prestaciones, teniendo en cuenta para ello su grado y nivel y la fecha de efectividad de su reconocimiento. Para profundizar en esta cuestión resulta de interés la consulta del trabajo de Torres Lopez M.A.: "El sistema de Autonomía y Atención a la Dependencia" en Temas de la Administración Local, núm. 39, 2008. Ed. CEMCI.

${ }^{22}$ Concretamente, el párrafo 4 del apartado $3 .^{\circ}$ de la Exposición de Motivos de la Ley de Dependencia expresa que "La Ley establece un nivel mínimo de protección, definido y garantizado financieramente por la Administración General del Estado. Asimismo, como un segundo nivel de protección, la Ley contempla un régimen de cooperación y financiación entre la Administración General del Estado y las Comunidades Autónomas mediante convenios para el desarrollo y aplicación de las demás prestaciones y servicios que se contemplan en la Ley. Finalmente, las Comunidades Autónomas podrán desarrollar, si así lo estiman oportuno, un tercer nivel adicional de protección a los ciudadanos."
}

${ }^{23}$ Véase el artículo 10 de la Ley de Dependencia. 
y ejecución de las políticas públicas articuladas por el Estado. Y es que, como siempre, estos últimos, son los grandes olvidados de la Ley.

Efectivamente, mientras esta norma instituye a las Comunidades Autónomas, con pleno respeto al ejercicio de las competencias constitucionalmente asumidas, como principales responsables del desarrollo y ejecución de la Ley, desde el momento en que la propia Ley le otorga las funciones de planificar, coordinar, dirigir, y gestionar en su ámbito territorial los servicios y recursos en función del reconocimiento del grado y nivel de dependencia, las valoraciones y determinación de las ayudas, así como también, las facultades de inspección y evaluación de los centros y servicios prestados por privados, entre otras competencias de desarrollo ${ }^{24}$.

A las entidades locales, por su parte, la Ley de Dependencia sólo les ha atribuido la posibilidad de participar en la gestión de estos servicios de atención a las personas en situación de dependencia y cuando así lo prevea una Ley Autonómica; haciéndose depender la mejora, ampliación y desarrollo de las competencias que tradicionalmente vienen ejerciendo en materia de prestación de servicios sociales, y otras acciones asistenciales de las previstas en la cartera de servicios del SAAD, del nivel de cooperación que la Comunidad quiera establecer en su territorio. Por ello considero que, de alguna forma, la norma se olvida de las corporaciones locales, a las que apenas les dedica un "podrán" ${ }^{25}$, mermando así la garantía institucional a su autonomía para la gestión de los intereses locales ${ }^{26}$.

Es claro que la legislación estatal no puede ir más allá de lo preceptuado en esta materia, pues de otra forma estaría invadiendo las competencias

${ }^{24}$ Véase el Artículo 11.1 de la Ley de Dependencia. En virtud de dicho precepto, desde enero de 2007, cada una de las Comunidades Autónomas, algunas más que otras, han llevado a cabo sus competencias legislativas y ejecutivas en la materia, y han puesto en marcha el Sistema del SAAD generalmente contando con la colaboración y participación de las distintas Administraciones Públicas Territoriales, desarrollando así un auténtico sistema en red con el que llegar a todos. En este desarrollo, las Comunidades Autónomas que han dado mayor participación en el sistema a otras Administraciones Públicas, como son los Servicios Sociales Comunitarios de los Municipios, o de las Diputaciones Provinciales u otros organismos autónomos dependientes de la corporación local, han sido Andalucía, Asturias, Castilla León, Valencia, Murcia, Extremadura Madrid y Castilla la Mancha.

25 En concreto el artículo 12 de la Ley de Dependencia dispone que "1. Las Entidades Locales participarán en la gestión de los servicios (...), de acuerdo con la normativa de sus respectivas Comunidades Autónomas....” Y que “2. Las Entidades Locales podrán participar en el Consejo Territorial del Sistema para la Autonomía y Atención a la Dependencia en la forma y condiciones que el propio Consejo disponga."

${ }^{26}$ Sobre el debate de la garantía institucional de la autonomía local en España, ver; MuÑoz Machado, S.: Tratado de Derecho Municipal, tomo I, Capítulo I, Civitas, Madrid, 2003, 2. ${ }^{\text {}}$ Edición. 
autonómicas de concretar las potestades que competen a los municipios en materia de asistencia social, como competencia que en exclusiva han asumido las Comunidades Autónomas en sus respectivos estatutos de autonomía $^{27}$. Pero también es una realidad insoslayable que la gran mayoría de las Comunidades Autónomas no vienen respetando ese principio de lealtad institucional en el desarrollo legislativo de las materias que son de su competencia, obviando, en más de una ocasión y como sería deseable, la posibilidad del establecimiento de fórmulas de cooperación y asistencia activas con otras Administraciones, como pueden ser las entidades locales, para el eficaz ejercicio de sus competencias.

Teniendo en cuenta lo anterior, el Estado, como garante de ese principio, podría haber incidido más en esa necesidad de participación de las entidades locales en el Sistema, para una más eficaz gestión del mismo, y para que su puesta en práctica se transforme en un éxito en todas las partes del territorio español ${ }^{28}$. Y no es que se pretenda una intervención a la autonomía de que disponen las Comunidades Autónomas en la configuración competencial de los gobiernos locales en materias que son de su competencia exclusiva, sino que apuntamos hacia la necesidad de que una ley básica, como es la Ley de Dependencia, haya de articular la actividad administrativa, en una materia en la que la armonización estatal se hace imprescindible para evitar los desequilibrios territoriales que se venían produciendo en ma-

${ }^{27}$ Vid artículo 2.1 de la Ley 7/1985, de 2 de abril, Reguladora de las Bases del Régimen Local, donde se establece que ..."Para la efectividad de la autonomía garantizada constitucionalmente a las entidades locales, la legislación del Estado y la de las Comunidades Autónomas, reguladora de los distintos sectores de acción pública, según la distribución constitucional de competencias, deberá asegurar a los Municipios, las Provincias y las Islas su derecho a intervenir en cuantos asuntos afecten directamente al círculo de sus intereses, atribuyéndoles las competencias que proceda en atención a las características de la actividad pública de que se trate y a la capacidad de gestión de la entidad local, de conformidad con los principios de descentralización y de máxima proximidad de la gestión administrativa a los ciudadanos."

${ }^{28}$ En este sentido la STC 64/1990, de 5 de abril ya estableció que "Todos los poderes públicos deben observar en el sistema autonómico un comportamiento leal, en uso de sus atribuciones, existiendo un deber de auxilio recíproco, de apoyo y de mutua lealtad, concreción del más amplio deber de fidelidad a la Constitución, deber que está igualmente vigente y ha de ser atendido entre los poderes de las diversas Comunidades Autónomas, las cuales, en el ejercicio de sus competencias, deben abstenerse de adoptar decisiones o realizar actos que perjudiquen o perturben el interés general y deben, por el contrario, tener en cuenta la comunidad de intereses que las vincula entre sí y que no puede resultar disgregada o menoscabada a consecuencia de una gestión insolidaria de los propios intereses." En estos supuestos de concurrencia de intereses, si no se alcanzase una solución de consenso, ha señalado el Tribunal Constitucional que "la decisión final corresponde al titular de la competencia prevalente", de modo que "el Estado no puede verse privado del ejercicio de sus competencias exclusivas por el ejercicio de una competencia, aunque también sea exclusiva, de una Comunidad Autónoma” (STC 56/1986). 
teria de asistencia social. Y esto tiene su apoyo en aquella posición doctrinal que entiende que las bases estatales han de ir referidas a la actividad administrativa dentro de la atribución competencial que el artículo 149.1.18 de la Constitución otorga al Estado en materia de regulación de las bases del régimen jurídico de las Administraciones públicas ${ }^{29}$.

Aunque, pese a al apoyo jurisprudencial y doctrinal que podamos encontrar en torno a la tesis que exponemos, somos conscientes que, por la situación política que en la actualidad está pasando el país en materia de concreción definitiva del Estado Autonómico, en más de una ocasión este papel, que corresponde al Estado, en materia de armonización de la actuación de las Administraciones públicas ante la defensa de los intereses generales que han de proteger, se hace más cuesta arriba de lo que sería deseable para el desarrollo del Estado de Bienestar que pretendió otorgarnos nuestra Constitución; y es que frecuentemente, en esta redefinición de los diferentes niveles de poder en que se articula el Estado, las Comunidades Autónomas se olvidan que estamos en un Estado unitario y que, como tal, el Estado ha de jugar un papel importante en la armonización de regímenes jurídicos en todas las partes del territorio español, aun cuando se trate de competencias asumidas en exclusiva por las Comunidades Autónomas ${ }^{30}$.

La segunda conclusión hace referencia a las necesidades de ampliación del Sistema reconocido en la Ley de Dependencia. Si como hemos visto, una de las finalidades de esta norma es la articulación de un Sistema para la Autonomía y Atención a la Dependencia que sea integral, y que como ya se hiciera con la LIONDAU, que abarque todos los ámbitos de la vida personal y social del discapacitado mediante el establecimiento de todo un sistema de protección social que comprometa a los tres niveles de gobierno en que se articula el Estado.

Y para este fin la Ley lo que establece es una serie de mecanismos de cooperación entre la Administración General del Estado, las Comunidades Autónomas, y las Entidades Locales, a fin de que puedan acordar solidas formas de colaboración y de desarrollar, a partir del marco competencial prefijado en el Consejo Territorial del Sistema, un modelo innovador, integrado, basado en la cooperación interadministrativa y en el respeto a las competencias.

${ }^{29}$ Sobre esta posición de la funcionalidad de la legislación básica puede consultarse el trabajo de Camaño, F.: "Autonomía local y Constitución: Dos propuestas para otro viaje por el callejón del gato" en Revista Española de Derecho Constitucional, núm. 70, 2004, pp. 185 y ss.

30 Son los artículos 149.1.1 y 18, junto con el 150.3 de la Constitución, los que establecen las potestades estatales en materia de coordinación de las competencias legislativas a fin de garantizar la igualdad de los españoles en el ejercicio de sus derechos y de sus deberes constitucionales, aun en materias que son de competencia exclusiva de las Comunidades Autónomas. 
Entonces podemos decir que, a día de hoy, los objetivos planteados por la Ley de Dependencia, un año y medio después de su aprobación, no se están cumpliendo ya que hasta el momento, son pocas las Comunidad Autónomas que han ha ampliado ese nivel mínimo de protección establecido y garantizado financieramente por el Estado; aun cuando son funciones que les corresponde desarrollar, no ya por imperativo de la Ley de Dependencia, sino que han de hacerlo en cumplimiento de las competencias que en materia de asistencia social, servicios sociales y sanidad han asumido estatutariamente ${ }^{31}$.

Además, la configuración de estos tres niveles de protección constituye un elemento determinante de desigualdad territorial, en tanto en cuanto la provisión de servicios que se consideren necesarios para la promoción de la autonomía personal en relación a los grados y niveles de dependencia se hacen depender, nuevamente, del nivel, de protección adicional que cada Comunidad Autónoma quiera y pueda establecer, lo que se aleja de ese deseo de regular unas condiciones básicas que garanticen la igualdad en el acceso a estas prestaciones sociales en todo el territorio español.

Por tanto, nuevamente la mejora en la eficacia de las funciones de interés general atribuidas a las Administraciones públicas y especialmente, el ejercicio y aumento de las funciones de defensa de los intereses locales asumidas por las entidades locales, depende de la voluntad de la Comunidad Autónoma. La auténtica gestión del Sistema se queda, en la letra de la Ley, en las Comunidades Autónomas. Son éstas las responsables últimas de dar el paso a un mayor grado de descentralización y eficacia a los servicios sociales y ayudas reconocidas en la Ley, en plena coherencia con el sistema de distribución de competencias. Pero en ese camino, el papel de nuestras corporaciones locales, ha quedado relegado al interés que se tome la Comunidad Autónoma en desarrollar y descentralizar la gestión más allá de las fronteras del gobierno regional, y de ese nivel mínimo garantizado por el Estado en esta norma, mermándose así las posibilidades de avance en cuarto pilar del Estado de Bienestar que se pretende garantizar a través de esta Ley de Dependencia.

Es por todos sabido que la descentralización de la gestión es vital para garantizar que los servicios se brinden en tiempo y forma, de acuerdo a las

${ }^{31}$ En este sentido, se dictó el Real Decreto 6/2008, de 11 de enero, por donde se determina el nivel mínimo de protección que se garantiza a los beneficiarios del Sistema para la Autonomía y Atención a la Dependencia en el ejercicio 2008 y donde se establecen las cuantías para el nivel minimo de protección garantizado por la Administración General del Estado, las cuales solo van destinadas a un grupo de Discapacidad de los definidos en el artículo 9 de la Ley de Dependencia, y en unas cantidades que, en todo caso deberían verse complementadas con las que establezca adicionalmente las Comunidades Autónomas. 
necesidades de la gente, por eso es importante trabajar porque la efectividad práctica de llevar a cabo ese tercer nivel de protección que se prevé en la Ley. Hay que ir más allá del contenido mínimo garantizado por el Estado, y hay que hacerlo de forma coordinada y al unísono en todas las Comunidades Autónomas, y que estas trabajen en colaboración con todas las entidades locales.

Porque, insistimos, lo más importante que esta Ley hace es reconocer un nuevo derecho universal y subjetivo de ciudadanía que trata de garantizar la atención y cuidados necesarios para la autonomía personal de las personas dependientes y para que la libertad y la igualdad sean una realidad tangible para el colectivo al que se dirige esta norma. Y para su desarrollo, para garantizar que este derecho a la ciudadanía sea una realidad para las personas discapacitadas o que se encuentran en situación de dependencia, es por lo que se ha puesto en marcha el Sistema de Autonomía y Atención a la Dependencia analizado. Pero ese Sistema puede ser eficaz, sin esa colaboración interadministrativa, y principalmente, sin la colaboración de las Comunidades Autónomas quienes deben llevar a cabo el desarrollo y ampliación de esos niveles de protección adicionales recogidos en la Ley, pues como se expresa en la propia Exposición de Motivos la propia naturaleza del objeto de esta Ley requiere un compromiso y una actuación conjunta de todos los poderes e instituciones públicas, por lo que la coordinación y cooperación con las Comunidades Autónomas, y éstas con sus entes locales, es un elemento fundamental para su éxito.

\section{LA INCORPORACIÓN DEL CONCEPTO DE CIUDADANÍA A LAS NUEVAS POLÍTICAS DE ATENCIÓN A LAS PERSONAS EN SITUACIÓN DE DEPENDENCIA}

En este trabajo en el que tratamos de resaltar el insoslayable papel que los gobiernos locales han de tener en la articulación de una política nacional de atención a las personas con discapacidad o en situación de dependencia, es imprescindible introducir un apartado que nos hable de la importancia que para este tipo de políticas sociales tiene el concepto de ciudadanía de que estamos hablando, sobre todo desde que la Ley 39/2006, de 14 de diciembre, de Promoción de la Autonomía Personal y Atención a las personas en situación de dependencia, fijara como objeto de la misma, "regular las condiciones básicas que garanticen la igualdad en el ejercicio del derecho subjetivo de ciudadanía”.

No nos dice nada más de este concepto, no nos explica en qué se ha de concretar ese derecho de ciudadanía, y en principio pareciera una mera de- 
claración retórica en el objeto de la Ley cargada de buenas intenciones, pero que luego no encuentra una concreción en el desarrollo de su articulado. Sin embargo, de alguna manera, todo el texto de la Ley está impregnado del reconocimiento de ese derecho, y principalmente los principios rectores de la norma, bajo los que subyacen toda la filosofía del movimiento vida independiente de que hablábamos en paginas anteriores.

En este contexto, el derecho a la ciudadanía va más allá del ejercicio de los derechos políticos que tradicionalmente se atribuyen al mismo, para impregnarse de ese mandato que el constituyente impuso a los poderes públicos de promover las condiciones para que la libertad y la igualdad del individuo y de los grupos en que se integra sean reales y efectivas; así como la de remover los obstáculos que impidan o dificulten su plenitud, facilitándose así la participación de todos los ciudadanos en la vida política, económica, cultural y social $^{32}$. Llegados a este punto, y en la medida en que la Ley no nos dice mucho más, habremos de preguntarnos ¿En qué se ha de concretar pues este derecho subjetivo a la ciudadanía?

Si bien no hay un concepto univoco de ciudadanía, podemos definirla, con carácter general, como la relación que vincula a todos los miembros de una comunidad política, y que, en función de la mayor o menor complejidad de la organización territorial y política de un país, se ve fragmentada en múltiples expresiones que determinan diversas y heterogéneas formas de participación en la "cosa pública". Pero para que esa participación en los asuntos públicos y para que esa relación con la comunidad sea real y efectiva, es una condición esencial la existencia de garantías suficientes que permitan el goce de los derechos subjetivos en igualdad de condiciones a todos los ciudadanos. Y ello, más aún, desde el momento en que, la sociedad civil, concepto que a menudo se hace cargo de la reformulación de la idea ciudadana, se considera que ha de ser siempre universal y democrática, de forma que sea realmente representativa de ese conjunto heterogéneo de organizaciones, asociaciones, sujetos y movimientos sociales que coexisten en el territorio. Pues para que esto sea así, es preciso garantizar la igualdad de oportunidades en el acceso a esa condición de ciudadanía y hacer llegar esa garantía a cualquier parte del territorio ${ }^{33}$.

Dicho de otro modo, los sujetos adquieren la categoría de ciudadanos, en un sentido amplio, cuando gozan efectivamente de todos aquellos derechos civiles, políticos, sociales, económicos, culturales, en incluso de los derechos de solidaridad — derechos de tercera generación-. Derechos que,

32 Artículo 9.2 de la Constitución.

33 En esta línea Aвramovich, V. y Courtis, C.: El umbral de la ciudadanía. El significado de los derechos sociales en el Estado social constitucional, Argentina, 2006, Ed. Del Puerto. 
más allá de concretarse simplemente para garantizar el bienestar de la ciudadanía, se configuran también desde esta óptica política mediante la cual todos los miembros de una sociedad deben tomar parte, en igualdad de condiciones, en las decisiones acerca de los asuntos que les afectan.

En efecto, actualmente, hablar de ciudadanía nos lleva a pensar en los sujetos reales que tienen la posibilidad o imposibilidad de ejercer esta condición. Por ello, un requisito indispensable para comenzar a poner en marcha mecanismos de construcción de ciudadanía es garantizar la inclusión de todos en proyectos comunes. Y esto no significa negar las diferencias, sino, por el contrario, construir a partir de las diferencias un sentido de pertenencia a espacios colectivos y de corresponsabilidad en los asuntos públicos.

Este desafío de la inclusión o de la integración social requiere apuntar a una serie de objetivos que sólo pueden ser conseguidos desde la política: articulación de intereses diversos, garantías de igualdad ante la ley, pleno ejercicio de los derechos, igualdad de oportunidades de acceso a la educación, la salud, al trabajo y la cultura y a todos los ámbitos de la vida social. Y no se trata, insistimos, simplemente de generar programas sociales y culturales para construir ciudadanía, sino de impregnar cada una de las acciones en estos campos de la idea del "ciudadano sujeto de derechos humanos".

Pero, lamentablemente, la forma en la que hoy por hoy está organizada nuestra sociedad lleva a que muchos sujetos pertenecientes a grupos minoritarios, marginales, y muy especialmente las personas con discapacidad o en situación de dependencia no sean capaces de ejercer plenamente sus derechos fundamentales, y sean excluidos socialmente de este concepto de ciudadanía que estamos manejando.

En efecto, los datos estadísticos disponibles nos muestran que las personas con discapacidad y en situación de dependencia sufren niveles inaceptablemente bajos de educación y empleo ${ }^{34}$. Asimismo, un gran número de personas dependientes, principalmente, pertenecientes al colectivo de personas mayores, aunque también perteneciente al colectivo de personas con dependencia por razón de discapacidad, se encuentran viviendo en situaciones de pobreza en comparación con los ciudadanos no dependientes, consecuencia directa del fracaso de las políticas sociales de atención a las personas en situación de dependencia, y en concreto, porque no decirlo, de las políticas educativas y de

34 Pese a los intentos de lograr una plena integración de este colectivo, a través de distintas leyes y planes de acción, en concreto, en materia de empleo, el porcentaje de personas con discapacidad inactivas, es decir las que ni trabajan ni buscan trabajo, supera el $66 \%$. Solo el $28 \%$ estaban ocupadas en 2006, mientras que la tasa de empleo del conjunto de la población en edad laboral es del 48\%. "Encuesta Comunitaria de Fuerza de Trabajo" (EFT), incluida en la "Encuesta de Población Activa”, INE, 2007. 
inserción laboral articuladas al efecto ${ }^{35}$. Una encuesta del CIS del año $2006^{36}$ refleja bien estos datos al indicar que dos de cada tres españoles consideran insuficiente la ayuda a discapacitados y personas en situación de dependencia. Los principales resultados de dicho estudio fueron los siguientes:

- Tres de cada cuatro encuestados consideran que los servicios sanitarios y sociales que se proporcionan a este colectivo son insuficientes.

- Los españoles siguen pensando que las Administraciones públicas son las principales responsables de mejorar la integración y las condiciones de vida de dependientes.

- En cuanto a la integración laboral, el 85,2 está convencido de que las dificultades para encontrar trabajo son mayores para estas personas.

- También hay consenso a la hora de afirmar que las personas con discapacidad y en situación de dependencia tienen que enfrentarse cada día a innumerables barreras arquitectónicas y sociales que limitan su vida. (En concreto, un 89,5 por ciento dice que les resulta muy difícil acceder a los transportes públicos; un 77,8 a museos y un 73 a hoteles y restaurantes) $)^{37}$.

Quizás, por lo anterior es por lo que la recién aprobada Ley 39/2006, de 14 de diciembre, de promoción de la autonomía personal y atención a las

35 Nos referimos en concreto a estas dos materias, educación y empleo, precisamente porque, es común la consideración de que hay dos elementos esenciales para la lucha contra la exclusión social y la pobreza que afecta a este colectivo cuales son: a) proporcionar una educación de calidad para todos los ciudadanos, en igualdad efectiva de oportunidades y adaptada a sus necesidades, con la colaboración de todos los componentes e instituciones de la comunidad educativa y, en general, de la sociedad en su conjunto y; b) Fomentar la participación en el empleo y en el acceso a los recursos, derechos, bienes y servicios para las personas en situación o riesgo de exclusión. Estos elementos siempre han sido un objetivo en los sucesivos Planes $\mathrm{Na}$ cionales para la Inclusión Social del Reino de España que el Gobierno viene desarrollando desde la Cumbre de Niza de 2003.

36 Barómetro de marzo 2007, Estudio N. 3483.

37 En esta materia, y según la Encuesta de Discapacidad, Autonomía personal y situaciones de Dependencia (EDAD) realizada, el 4 de noviembre de 2008, por el INE; los problemas de movilidad son el primer tipo de discapacidad. Los principales grupos de discapacidad de las personas de seis y más años residentes en hogares son los de movilidad (que afecta al 6,0\% de la población), vida doméstica $(4,9 \%)$ y autocuidado $(4,3 \%)$. De hecho, más de la mitad de las personas con discapacidad tienen limitaciones en su actividad debido a alguno de estos tres motivos. Para el grupo de 80 y más años estos tres principales grupos de discapacidad afectan a siete de cada 10 personas con discapacidad. Dentro del grupo de movilidad, la restricción de desplazarse fuera del hogar afecta a dos de cada tres personas con problemas de movilidad. Para mayor información al respecto se puede consultar Jimenez LaRA, A.: "La población con discapacidad: estudios demográficos", en VV.AA.: Tratado sobre discapacidad, Aranzadi, Navarra, 2007. 
personas en situación de dependencia, fija como objeto de la misma, "regular las condiciones básicas que garanticen la igualdad en el ejercicio del derecho subjetivo de ciudadanía(...)mediante la creación de un Sistema para la Autonomía y Atención a la Dependencia, con la colaboración y participación de todas las Administraciones Públicas y la garantía por la Administración General del Estado de un contenido mínimo común de derechos para todos los ciudadanos en cualquier parte del territorio del Estado español”.

Llama poderosamente la atención la proclamación y el reconocimiento de este "derecho subjetivo de ciudadanía". Podemos decir que en concreto, dicha formulación constituye una de las innovaciones más resaltables de esta norma que, inicialmente, no reconocía expresamente un nuevo, y aun menos, tan específico Derecho. Derecho que como acabamos de ver, requiere de un esfuerzo doctrinal y jurisprudencial para encajarlo ex Novo en nuestro Ordenamiento Jurídico. Pues hoy por hoy, no es fácilmente reconocible en nuestro ordenamiento la expresión "derecho subjetivo del ciudadano". Aunque esa operación no ha de resultar muy compleja por cuanto, en definitiva, como acabamos de ver, este nuevo derecho subjetivo no hace alusión a otra cosa que al reconocimiento del derecho a acceder y ejercer, en igualdad de oportunidades, los derechos y libertades fundamentales que la Constitución reconoce a todos los ciudadanos del territorio nacional.

\subsection{LA IMPORTANCIA DEL RECONOCIMIENTO DE LOS DERECHOS DE CIUDADANÍA PARA LOS GOBIERNOS LOCALES}

De lo anterior se deduce que los derechos de ciudadanía van orientados a lograr la igualdad real y efectiva de todos los individuos, y en los casos de las personas con discapacidad o en situación de dependencia, a que estos puedan acceder en igualdad de condiciones al ejercicio de los derechos y libertades que cada ciudadano tiene por el hecho de serlo, sin tener en cuenta sus condiciones personales o capacidades. Es procurar que el colectivo de personas que padecen una disminución de su autonomía funcional o con discapacidad no se sienta excluido de una sociedad que no está adaptada a ellos, y que nació sin contar con su presencia, pero que poco a poco trata de articularse para crear una sociedad inclusiva y que sea de todos.

Pero como sabemos, en España, las políticas contra la exclusión social presentan una triple complejidad. Por una parte, se insertan de lleno en la lógica del gobierno multinivel. Todas las esferas territoriales de gobierno tienen algún tipo de presencia institucional en la lucha contra la exclusión social de colectivos. Y, más relevante aún, crece el convencimiento sobre la interdependencia entre dichas esferas, a la hora de afrontar la inmensa ma- 
yoría de problemáticas. Por otra parte, la política social contra la exclusión se presenta fragmentada en un amplísimo abanico de programas, servicios e instrumentos de acción pública. En el marco de este complejo panorama, a continuación aportaremos algunas notas de síntesis en relación a un componente institucional clave en la estrategia contra la exclusión, y al que, paradójicamente nuestra Constitución presta una escasa atención: el sistema público de base autonómica de servicios sociales.

Los servicios sociales son una de las piezas más vulnerables en la arquitectura institucional del estado de bienestar español. Por un lado, su normativizarían es débil, por cuanto no fueron incorporados, en el bloque constitucional-estatutario, al campo de los derechos sociales de ciudadanía. Por otro lado, su demanda está poco articulada, y no existe una opinión pública de apoyo claro a la extensión de los servicios: muchos barrios se han movilizado en demanda o defensa de escuelas y hospitales; ¿cuántos lo han hecho en demanda de, por ejemplo, programas de salud mental, centros de día, o servicios de atención domiciliara?

Todo ello ha ido apartando a los servicios sociales en España de una concepción universalista, de tipo socialdemócrata; por el contrario, los ha situado en tasas de cobertura e intensidad mucho más selectivas y débiles. En ese contexto -y esta puede ser la otra cara de la moneda - los servicios sociales han tendido a orientar y focalizar su trabajo hacia los grupos de riesgo: personas y sectores muy vulnerables a la marginación, o bien en situaciones abiertas de precariedad social. Así pues, la conexión entre servicios sociales y exclusión por razón de la discapacidad o dependencia se ha ido haciendo cada vez más fuerte ${ }^{38}$.

Quisiéramos también destacar la importancia del protagonismo público y social en la lucha por la inclusión social. Pensamos que en sociedades complejas como las nuestras los resortes clave de lucha contra la exclusión deben ubicarse en la esfera pública; no obstante estamos centrando nuestra atención en este trabajo, no lo olvidemos, con un sector público en plena reformulación; hoy en día nadie niega que estamos asistiendo a una redefinición de los esquemas estructurales tradicionales en que se han movido los distintos niveles de gobierno en España, la tendencia, se orienta hacia una redefinición de las competencias públicas de forma que el nuevo Estado-Nación habrá de de articular su papel, más que como ejecutor de políticas públicas, como gran redistribuidor que garantice la solidaridad y el equilibrio social entre ciudades y territorios y entre individuos.

38 Subirats, J.: Algunas Reflexiones sobre la Exclusión Social y las Políticas Públicas de Respuesta: una Perspectiva desde España, Documento preparado para el seminario Buenas Prácticas en Inclusión Social: Diálogo Entre Europa y América Latina y El Caribe, Milán, 21 y 22 de marzo de 2003. 
Las reformas del Estado a que estamos asistiendo suponen reconsiderar el papel de éste, quien deberá asumir el compromiso de la solidaridad, la equidad y el equilibrio interterritorial; y a la vez implica, ineludiblemente, el fortalecimiento institucional del municipio como instrumento idóneo para cerrar la brecha social que puede abrir en la comunidad la exclusión de colectivos, porque son los entes locales quienes deben asumir el papel de articulador y promotor de las expectativas y deseos de la comunidad local.

Así, las políticas sociales, los programas y los servicios impulsados desde múltiples niveles territoriales de gobierno, pero con mayores responsabilidades de impulso del gobierno local, se han de convertir en las piezas fundamentales de cualquier proyecto de sociedad cohesionada que se precie. Las políticas sociales contra la exclusión deben abandonar cualquier pretensión monopolista, profesionalista o centralizadora ya que su papel como palancas hacia el desarrollo social inclusivo será directamente proporcional a su capacidad de tejer sólidas redes de interacción con todo tipo de agentes comunitarios y asociativos, en el marco de sólidos procesos de deliberación sobre modelos sociales, y bien apegadas al territorio.

\subsection{LA DEPENDENCIA EN LA DISTRIBUCIÓN DE COMPETENCIAS: El reparto de papeles en el Estado Autonómico}

Hemos visto como el modelo actual de tratamiento de la dependencia fija como objetivo potenciar la autonomía e independencia personal. También hemos advertido al principio de este trabajo como el tratamiento del problema ha pasado de lo individual a lo colectivo: la cuestión no es tener una discapacidad sino la desventaja que esa situación comporta en el ámbito social en el que la persona se integra.

Asimismo acabamos de analizar algunos de los fundamentos constitucionales que apoyan la afirmación de que las personas con discapacidad o en situación de dependencia han de tener los mismos derechos que los demás ciudadanos. Sin embargo, en la práctica, nuestras sociedades se organizan de una manera que suelen impedir que estas personas disfruten de todos los derechos fundamentales. Este es el motivo por el que la discapacidad y la dependencia a otras personas para la realización de las actividades básicas de la vida diaria es un aspecto de derechos humanos y ello debería ser el punto de partida de toda política en la materia.

El contraste entre derechos y realidad es patente. De ahí que estemos considerando en este trabajo como un factor clave para el éxito del Sistema planteado en la Ley de Dependencia el que nuestras Administraciones públicas reconozcan que el nuevo enfoque de la garantía de la protección de los 
derechos de las personas en situación de dependencia obliga a que se adopte un marco básico del Estado, una legislación estatal, que articule un sistema de protección mínima para este colectivo, y que deberá ser desarrollado por las correspondientes Comunidades Autónomas garantizando que su ejecución se lleve a cabo por las respectivas entidades locales, por cuanto los problemas y los censos de población con discapacidad difieren en función del territorio en que nos encontremos.

Por ello, para, completar este apartado, es preciso hacer referencia al fundamento constitucional de la intervención de los poderes públicos en la materia con la finalidad de identificar los fundamentos de esta necesaria redefinición del papel que corresponde desarrollar a los gobiernos locales en la aplicación y desarrollo de la Ley de Dependencia, y para dar cuenta del déficit competencial que están padeciendo desde la aprobación de esta Ley. Ya que en este aspecto la Ley solo ha realizado una suerte de reparto competencial a los dos niveles territoriales superiores de gobierno, y solo se ha referido a las competencias que podrán asumir los entes locales en esta materia en dos apartados, y en cuya dicción literal, deja a la decisión de la Comunidad Autónoma el papel que estos han de asumir en la gestión del Sistema para la Autonomía y Atención a la Dependencia.

\section{2.a) Las competencias Estatales}

La competencia estatal en esta materia tiene su fundamento en diversas disposiciones de rango constitucional. Por un lado el artículo 1.1 CE, que proclama un "Estado social y democrático de Derecho, que propugna como valores superiores de su ordenamiento jurídico la libertad, la justicia, la igualdad y el pluralismo político".

También en el citado artículo 9.2 CE, el cual, dispone que corresponde a los poderes públicos "promover las condiciones para que la libertad y la igualdad del individuo y de los grupos en que se integra sean reales y efectivas; remover los obstáculos que impidan o dificulten su plenitud y facilitar la participación de todos los ciudadanos en la vida política, económica, cultural y social".

Por su parte, el artículo $14 \mathrm{CE}$, el cual proclama que "los españoles son iguales ante la ley, sin que pueda prevalecer discriminación alguna por razón de nacimiento, raza, sexo, religión, opinión o cualquier otra condición o circunstancia personal o social" 39 .

39 El grado de protección del artículo 14 de la Constitución, se plasma en la posibilidad de acudir a los Tribunales ordinarios a través de un procedimiento basado en los principios de preferencia y sumariedad y, agotada la vía jurisdiccional ordinaria, la vulneración de dicho pre- 
Y finalmente, el artículo $49 \mathrm{CE}$, que como sabemos, ordena a los poderes públicos para que realicen "una política de previsión, tratamiento, rehabilitación e integración de los disminuidos físicos, sensoriales y psíquicos, a los que prestarán la atención especializada que requieran y los ampararán especialmente para el disfrute de los derechos que(...) la constitución otorga a todos los ciudadanos.

De esta forma vemos cómo nuestra Constitución avala de forma clara que, a partir del reconocimiento de la existencia real de condiciones de desigualdad entre los ciudadanos por múltiples factores, es preciso un compromiso de los poderes públicos en la promoción de la libertad y de la igualdad. Legitimando, por consiguiente, las medidas que fomenten la igualdad de oportunidades, no siendo contradictoria la llamada "discriminación positiva” con el principio de no discriminación antes enunciado ${ }^{40}$.

cepto puede ser objeto de recurso de amparo ante el Tribunal Constitucional en virtud de lo dispuesto en el art. 53 de la CE.

${ }^{40}$ En este marco conceptual, en el que se asume que la situación de desventaja social es el elemento clave en el tratamiento del problema, surge con fuerza la idea de la igualdad como diferenciación. Ambos conceptos se relacionan de dos formas distintas: la primera, diferenciación para la igualdad, indica que el fin de una sociedad más igualitaria, considerada más justa, exige políticas que traten desigualmente a quienes son desiguales con objeto de reducir la situación de desventaja; la segunda, diferenciación como igualdad, tiene el significado de la aspiración de una sociedad igualitaria en la que las relaciones sociales se caracterizan por una diferenciación o diversidad entre los distintos grupos que no implica ni dominación ni relación injusta entre ellos.

Podemos observar que, en la práctica, existen innumerables políticas basadas en la primera acepción de la diferenciación para la igualdad, por ejemplo la de viviendas protegidas, la dotación de becas o las subvenciones a la contratación laboral de colectivos desfavorecidos, así como que de dichas medidas se benefician ciertas minorías que se encuentran en situación desfavorecida o incluso grupos muy numerosos, como es el de las mujeres, que son la mitad de la población, o las personas con discapacidad. Se trata, en definitiva, de lo que venimos llamando medidas de discriminación inversa o positiva, cuya traslación a las normas jurídicas nacionales o internacionales se ha ido produciendo en las tres últimas décadas con mejor o peor fortuna, pero que, sin duda, han marcado un hito en el tratamiento jurídico de los colectivos en situación de desventaja o desfavorecidos. Sobre estos conceptos es de sumo interés la consulta al trabajo de Ruis, M.: "La igualdad como diferenciación", en Derechos de las minorías y de los grupos diferenciados, Escuela Libre Editorial, 1994. El tratamiento de esta cuestión ha recibido una plena aceptación por la Jurisprudencia Constitucional. Desde la primera Sentencia de nuestro Tribunal Constitucional, la 128/1987, de 16 de julio, en la que se reconoce la constitucionalidad de una medida próxima a la discriminación inversa, llegamos hasta la Sentencia del mismo Tribunal 28/1992, de 29 de marzo, en la que se reconocen como constitucionales aquellas medidas que tiendan a compensar una desigualdad real de partida.

En relación a las personas con discapacidad, cabe hacer referencia a la Sentencia del citado Tribunal, la 269/2004, en la que se da por válida la adopción de medidas promocionales de la igualdad de oportunidades que "tienden a procurar la igualdad sustancial de sujetos que se encuentran en condiciones desfavorables de partida", poniendo de relieve la conexión da las medidas positivas con el artículo 9.2 y 49 de la Constitución. 
En cuanto a la norma que propiamente realiza el reparto competencial entre el Estado y las Comunidades Autónomas. Hay que señalar en primer término que el artículo 149.1.1. ${ }^{a}$ de la Constitución constituye un título competencial "con contenido propio, no residual", conforme ha interpretado el Tribunal Constitucional, (STC 172/1998 de 23 de julio), que otorga al Estado las facultades normativas para determinar las condiciones básicas de la igualdad y no discriminación de las personas con discapacidad o en situación de dependencia, de manera que se les garantice los mismos derechos y prestaciones en todo el territorio nacional ${ }^{41}$.

No obstante, este título competencial no alcanza, sin embargo, a regular la totalidad del régimen jurídico de la materia sobre la que trate la norma. Aquí entraría en juego el marco competencial del Estado, las Comunidades Autónomas y las corporaciones locales.

En efecto, según la STC 212/2005 de 21 de julio, debe distinguirse, de un lado, entre los elementos generales conformadores del derecho que se trate, imparables en el articulo 149.1.1. a alcanzables por las normas de rango legal y, cumpliendo determinadas exigencias de rango reglamentario y, de otro, los criterios de la política sectorial correspondiente, en particular, en el presente caso, cabría mencionar los de asistencia social y servicios sociales, accesibilidad y voluntariado ${ }^{42}$.

${ }^{41}$ El Tribunal Constitucional, en una consolidada doctrina ha delimitado el objeto y contenido del título competencial basado en el artículo 149.1.1. a así nos dice que el Estado tiene competencias exclusivas para incidir sobre los derechos y deberes constitucionales desde una concreta perspectiva, la de garantizar lo que las SSTC 61/1997, de 20 de marzo y 173/1998, de 23 de julio, han denominado como la "igualdad de posiciones jurídicas fundamentales" -Se entiende como "posiciones jurídicas Fundamentales", "facultades elementales, límites esenciales, deberes fundamentales, prestaciones básicas, ciertas premisas o presupuestos previos"-. En este sentido, es importante matizar dos cosas: a) Que la materia objeto de regulación son los derechos constitucionales en sentido estricto y los deberes básicos. b) Que el elemento teleológico o finalista del artículo 149.1.1. ${ }^{a}$ no es otro que la igualdad de todos los españoles. Junto a la regulación de condiciones básicas, el Tribunal Constitucional ha tenido la oportunidad de precisar en varias Sentencias (SSTC 227/1988; 173/1998; 102/1995; 156/1995; 154/1988; 290/2000) que cabe incluir la regulación estatal de aquellos criterios que guardan una relación necesaria e inmediata con aquellas, tales como: El objeto o ámbito material sobre el que recaen las facultades que integran el derecho. Los deberes, requisitos mínimos o condiciones básicas en que ha de ejercerse un derecho. El marco organizativo que posibilite el ejercicio mismo del derecho (esto ha permitido amparar la competencia del Estado para regular, por ejemplo, la creación y funciones de la Oficina Nacional del Censo Electoral o de la Agencia Estatal de Protección de Datos). Y el establecimiento de un régimen sancionador.

${ }_{42}$ En este mismo sentido se ha pronunciado el Consejo de Estado, en su Dictamen 1579/2005 -referido a la LIONDAU_, en el que entendía que la jurisprudencia constitucional había venido delimitando el sentido u alcance del articulo 149.1.1. ${ }^{a}$ CE; señalando que dicho precepto, "mas que delimitar un ámbito material excluyente de toda intervención de las Comunidades Autónomas, lo que contiene es una habilitación para que el Estado condicione —-mediante, precisa- 
En definitiva, que la jurisprudencia constitucional exige que la regulación estatal de las condiciones básicas deje un margen de maniobra dentro del cual, las Comunidades Autónomas puedan ejercer dichas competencias sectoriales en materia de discapacidad y dependencia ${ }^{43}$. Pero que al mismo tiempo sirvan de condicionante para que en la atribución competencial que éstas realicen en el resto de entidades subnacionales, desarrollen también su papel de garantizar la igualdad de todos los españoles en el ejercicio de sus derechos y en el cumplimiento de sus deberes constitucionales.

\section{2.b) Las competencias de las Comunidades Autónomas}

Con todo, y entrando ya en las competencias autonómicas en materia de discapacidad, vamos a analizar el alcance de las mismas por dos vías. En primer lugar por los títulos competenciales atribuidos expresamente por la Constitución en exclusiva a las Comunidades Autónomas; y ello sin olvidar las competencias de desarrollo reglamentario que puedan tener sobre la legislación básica estatal. Y por otro, mediante el estudio de las competencias recogidas por cada unos de los estatutos de autonomía vigentes en las distintas Comunidades Autónomas en la materia, que básicamente alcanzan a materias relevantes para el tema que nos ocupa como es la asistencia social y servicios sociales, la accesibilidad y el voluntariado.

El Título VIII del Texto Constitucional deberá ser nuestro lugar de partida, y concretamente el artículo 148 del Texto Fundamental que señala que las Comunidades Autónomas podrán asumir competencias en una serie de materias; todas ellas en este momento ya asumidas.

De esta forma, el análisis sistemático de cada uno de los títulos competenciales descritos en los distintos apartados del artículo 148, más el apartado 3 del Artículo 149 que señala que "las materias no atribuidas expresamente al Estado por esta Constitución podrá corresponder a las Comunidades Au-

mente, el establecimiento de unas "condiciones básicas" uniformes - el ejercicio de las competencias autonómicas en la materia con el objeto de garantizar la igualdad de todos los españoles en el ejercicio de sus derechos u en el cumplimiento de sus deberes constitucionales"; de esta forma, el máximo intérprete de la Constitución nos recuerda que "la regulación amparada en dicho precepto no puede suponer una normación completa y acabada de los derechos y deberes, de forma que el mismo no debe ser entendido como un prohibición de divergencia autonómica”.

${ }^{43}$ De ahí que, con pleno respeto a la doctrina constitucional en la materia la Ley 39/2006, de 14 de diciembre, de Promoción de la Autonomía Personal y Atención a las personas en situación de dependencia haya articulado una serie de mecanismos de cooperación y coordinación como instrumentos fundamentales para la efectividad de la política planteada y los derechos subjetivos en la misma y fiel a la forma de distribución competencial que sobre la materia podemos encontrar en nuestra Carta Magna. 
tónomas en virtud de sus respectivos Estatutos de Autonomía", podemos extraer una primera lectura, atestiguada y confirmada, posteriormente, por los Estatutos de Autonomía y por un desarrollo legislativo autonómico bastante completo sobre supresión de barreras y promoción de la accesibilidad y de la igualdad de oportunidades a través de diversas medidas de acción positiva y de servicios sociales de apoyo; que la competencia para legislar sobre la materia de accesibilidad, asistencia social y servicios sociales, y ejecutivas en materia de seguridad social, empleo, educación, sanidad y otras materias recogidas en la constitución y en los respectivos estatutos de autonomía, y muy relacionadas con las necesidades especiales de este colectivo, son materias que también entran en las responsabilidades públicas de las Comunidades Autónomas, y no sólo es que tengan el derecho, sino que también tienen la obligación de regular y ejecutar con eficacia.

Y por supuesto, lo que no debe significar esa nueva regulación articulada a través de la Ley de Dependencia es una dejación de competencias de las Comunidades Autónomas o un dejarse llevar sin más y muchísimo menos no cumplir las normas que tengan aprobadas, es extremadamente importante la clarificación de ésta interrelación competencial con la legislación estatal aprobada en la materia, a fin de evitar conflictos que lo único que conllevarían serían retrasos en la deseada igualdad de oportunidades y no discriminación.

Veamos a continuación los fundamentos constitucionales de algunas de esas competencias autonómicas en la materia a que nos hemos referido a los largo de esta exposición, y que son, en definitiva, las que obligan a estas entidades territoriales a que cumplan con las funciones constitucional y estatutariamente atribuidas, y que den cumplimiento al necesario desarrollo normativo que la Ley de Dependencia precisa para alcanzar la igualdad efectiva de este colectivo en la sociedad.

\section{Accesibilidad $^{44}$}

La accesibilidad es una materia que corresponde nítidamente a las Comunidades Autónomas, con la participación en la ejecución de las entidades locales ${ }^{45}$.

${ }^{4}$ Sobre este concepto se puede consultar el libro de De Asis RoIG, R. (dir.): El significado de la accesibilidad universal y su justificación en el marco normativo español, Ministerio de Asuntos Sociales-Universidad Carlos III, Madrid, 2006.

45 Respetando el marco básico de la ley de Igualdad de Oportunidades 51/2007, y de las normas que fijen las condiciones básicas de accesibilidad, el desarrollo de las medidas que sean necesarias para alcanzar la "accesibilidad universal" definida en las mismas. 
En efecto, la competencia en materia de accesibilidad ha venido siendo asumida de manera exclusiva por las Comunidades Autónomas en virtud de los apartados $3 .^{\circ}, 4 .^{\circ}$ y $5 .^{\circ}$ del mencionado artículo $148 \mathrm{CE}$. Donde se establece como competencia exclusiva la ordenación del territorio, urbanismo y vivienda. Las obras públicas de interés en su propia Comunidad y el transporte que se desarrolle íntegramente en su Comunidad Autónoma; siendo la estatal una competencia de mera armonización o establecimiento de normativa básica, justificada por la necesidad de exigir una sustancial uniformidad en las condiciones de vida del colectivo de personas discapacitadas (Art. 149.1.1. ${ }^{\mathrm{a}}$ ); o bien amparada en otros títulos competenciales que puedan incidir de manera indirecta en cuestiones relativas a la accesibilidad ${ }^{46}$.

De esta forma, estos títulos competenciales introducen en esta materia una prioridad de competencias en favor de las Comunidades Autónomas en lo que se refiere a la regulación de la accesibilidad y la supresión de las barreras arquitectónicas en el medio urbano y en la edificación, las obras públicas y el transporte que discurra por el interior de su territorio ${ }^{47}$.

\section{Servicios Sociales y Asistencia Social}

Como hemos tenido oportunidad de advertir en paginas anteriores, la delimitación competencial en materia de servicios sociales entre el Estado y las Comunidades Autónomas ha sido confusa desde el momento en que la Constitución no atribuye expresamente esta competencia a ningún ente te-

$46 \mathrm{Al}$ amparo del reiterado titulo estatal armonizador en esta materia, basado en el artículo 149.1.1. ${ }^{a}$ se pronuncia la Sentencia del Tribunal Constitucional, núm. 61/97, de 20 de marzo. Así pues, si bien la competencia en materia de urbanismo es "exclusiva" de las Comunidades Autónomas, debe garantizarse la coexistencia de esta competencia con las competencias que el Estado tiene en virtud de los apartados del artículo 149.1 de la Constitución. Como más arriba se ha expuesto, el artículo 149.1.1. a faculta al Estado para fijar las condiciones básicas de igualdad de todos los españoles en el ejercicio de los derechos y cumplimiento de deberes constitucionales. En aplicación de estos títulos competenciales, el Estado ha dictado diversa normativa que de una u otra forma inciden de manera decisiva en la mejora de la accesibilidad y en la supresión de las barreras arquitectónicas a las que se enfrentan las personas discapacitadas (Ley 29/1994, de 24 de noviembre, de Arrendamientos Urbanos; Ley 49/1960, de 21 de julio, sobre Propiedad Horizontal; Ley 15/1995, de 30 de mayo, por la que se establecen límites al dominio sobre inmuebles para eliminar barreras arquitectónicas a las personas con discapacidad; o el Real Decreto 556/1989, de 19 de mayo, de medidas mínimas sobre accesibilidad en los edificios).

47 Estos entes territoriales han ido asumiendo, en todos los casos, dicha competencia, produciéndose el correspondiente traspaso de funciones y servicios. Las Comunidades Autónomas han hecho uso de este título competencial para legislar en materia de accesibilidad y supresión de barreras arquitectónicas, llegando incluso a dictar normas técnicas de obligado cumplimiento, y que luego han sido desarrolladas por las ordenanzas municipales que en la materia han dictado la práctica totalidad de las entidades locales. 
rritorial, ni tan siquiera se para a delimitar su significado. Ésta indeterminación respecto de los servicios sociales, es también extrapolable a la asistencia social, como veremos más adelante, con la diferencia de que -en la materia que nos ocupa- la Constitución no atribuye ni tan siquiera competencias sobre los mismos ${ }^{48}$.

En efecto, la competencia sobre los servicios sociales no figura en el artículo 149 CE, de ello pudo desprenderse que el Estado carecía de competencias sobre los mismos, aunque no puede negarse que, en el ámbito de actuación central, siempre existió una red de servicios sociales, tanto al margen de la Seguridad Social y por tanto situados en el ámbito estatal -servicios sociales en favor de menores, discapacitados ó ancianos, gestionados por un Instituto Nacional de Asistencia Social- como otros, incardinados en el ámbito de la Seguridad Social —básicamente, a través del anterior Instituto Nacional de Servicios Sociales-.

Tampoco quedaba claro que los servicios sociales se situasen dentro de las competencias que pueden asumir las Comunidades Autónomas, al no aparecer citados en el artículo $148 \mathrm{CE}$. El problema de la falta de delimitación y de distribución de competencias sobre los servicios sociales pudo resolverse por dos mecanismos:

- Los servicios sociales entrarían en las competencias de las Comunidades Autónomas, a través de una interpretación in extenso del artículo 148.1.20..$^{\circ}$ englobando a aquéllos dentro de un concepto amplio de "asistencia social".

- Desde otra perspectiva, los servicios sociales podrían ser asumidos por las Comunidades Autónomas, en cuando que no pertenecen a la competencia exclusiva del Estado (149.3 CE).

Cualquiera que sea el mecanismo de atribución, la realidad muestra que las Comunidades Autónomas han asumido estas competencias, incluyendo en los respectivos Estatutos de Autonomía competencias, tanto en servicios sociales genéricos, como específicos -por ejemplo, infancia, personas con discapacidad, tercera edad, etc ${ }^{49}$.

${ }^{48}$ Para algunos autores, no es que la Constitución se olvidara de la asistencia social y de los servicios sociales, sino que no se preocupó de identificarlos, al enviar la competencia sobre los mismos a las Comunidades Autónomas "tal vez porque el constituyente no se tomó en serio lo que eran y lo que debía o podía llegar a ser el desarrollo de estas materias", Vicente Paches, F.: "Asistencia Social y Servicios Sociales: régimen de distribución de competencias", Tribuna social: Revista de seguridad social y laboral, núm. 138, Madrid, 200, pp. 11-12.

${ }^{49}$ Las Comunidades Autónomas, como regla general, regulan un sistema de Servicios Sociales, como sistema público en favor de la Comunidad, entendiendo como servicios socia- 
Respecto a la materia de Asistencia Social ${ }^{50}$ se considera atribuible a las Comunidades Autónomas en virtud del tenor literal del Artículo 148.1.20. ${ }^{a}$ $\mathrm{CE}$, y de hecho estas han asumido dicha competencia en exclusiva. De esta forma en esta materia las Comunidades Autónomas tienen competencias legislativas, reglamentarias y de ejecución y gestión de sus servicios plenas. Por tanto la legislación del Estado solo puede tener valor supletorio o con finalidad armonizadora de lo que en esta materia dicten las Comunidades Autónomas ${ }^{51}$.

Sin embargo, como se dijo antes, la intervención estatal puede venir justificada por la necesidad de exigir una sustancial uniformidad en las condiciones de vida del colectivo de discapacitados, de manera que todos, sin acepción territorial, puedan beneficiarse de un mínimo de protección social. Ello fundamentado en el ya citado artículo $149.1 .1 .^{\circ} \mathrm{CE}$. De ahí que la jurisprudencia constitucional haya entendido admisible tales competencias "En la medida en que existan problemas sociales que precisen de un planteamiento global" ${ }^{52}$.

les —como la gran mayoría de la legislación autonómica en la materia define- como el conjunto de actuaciones que tiendan a la prevención, eliminación y tratamiento de las causas que conducen a la marginación e inadaptación sociales, al tiempo de favorecer y garantizar el pleno y libre desarrollo de la persona y de los grupos sociales dentro de la sociedad, promoviendo su participación en la vida cotidiana. Y para hacer efectiva la constitución de ese sistema autonómico de Servicios Sociales, todas las Comunidades no solo han asumido competencias exclusivas en esta materia en sus respectivos estatutos de autonomía, sino que también han ido aprobando leyes de servicios sociales, que responden a características propias que pueden agruparse en tres tipos: a) Leyes fundamentalmente declarativas, que podríamos decir que generan "derechos axiológicos". b) En una segunda fase, incorporación a las leyes de un cuadro de infracciones y sanciones, al menos respecto al sector privado de gestión de los Servicios Sociales. c) Una tercera fase más avanzada, en la que la ley fija derechos subjetivos, aunque en gran parte su efectividad está ligada a la existencia de consignación presupuestaria. Es el caso de las Leyes de Madrid, Ley 11/2003, de 27 de marzo, y Asturias, Ley 1/2003, de 24 de febrero.

${ }^{50}$ La diferencia entre Asistencia Social y Seguridad Social fue delimitada por el Tribunal Constitucional en la Sentencia 76/1986. En ella se declara que lo característico de la acción protectora derivada de la Asistencia Social es que no está integrada en el Sistema de Seguridad Social debido al carácter no contributivo de la misma. Sin embargo, el TC no ha impedido que prestaciones no contributivas se integraran también en el Sistema de Seguridad Social. En la misma línea Ángel Rodríguez Castedo, Director del IMSERSO, mencionó en el Seminario OISS. Seminario Internacional "Los sistemas de Protección frente a los retos del siglo XXI" celebrado el 30 de noviembre y el 1 de diciembre de 2006 en Santiago de Chile, que la necesidad de atender, desde el ámbito público, las situaciones de disminución de la autonomía funcional, llevó a considerar como derecho de seguridad social, la atención a situaciones de dependencia.

\footnotetext{
51 Véase arts. 149.3 y 150.3 CE.

52 STC 146/1986, de 25 de noviembre.
} 
En síntesis, en el ámbito de las Comunidades Autónomas, y sin perjuicio de la incidencia tangencial de determinados ámbitos de actuación de carácter estatal en la materia, se ha venido establecido una red de protección de carácter asistencial, en la que la gama de prestaciones y ayudas es amplia y heterogénea, con una regulación normativa que descansa en las Autonomías, a las que corresponde por igual, no lo olvidemos, el sostenimiento financiero de los mismos.

Antes de finalizar, también en este punto hay que hacer referencia a la mencionada indeterminación de la asistencia social en nuestra Constitución de lo que deriva, al tiempo, no solo que no exista una definición de lo que haya de entenderse por la misma, sino también su falta de delimitación clara con la Seguridad Social — que no deriva tanto de una confusión terminológica, cuanto de una equívoca situación normativa existente tanto en uno como en otro ámbito- ${ }^{53}$.

De esta forma vemos como la Constitución hace referencia a la asistencia social únicamente en el momento en que procede a distribuir las competencias entre la Administración Central y las Administraciones autonómicas, pero sin que, con carácter previo, haya existido una identificación a esta institución en los artículos anteriores de la Constitución.

Y de igual modo, también podemos observar como la Constitución se refiere simplemente de modo genérico a la creación de un sistema de servicios sociales, en orden a la garantía del bienestar de los ciudadanos en la tercera edad, sin que ello quiera decir que sea solamente este colectivo el

53 Han existido una multiplicidad de criterios para diferenciar la Seguridad Social y la asistencia social, entre los cuales podemos destacar los siguientes: 1. La naturaleza de las prestaciones -básicamente, económicas las de Seguridad Social y esencialmente de servicios, en lo que se refiere a la asistencia social-. 2. El condicionamiento contributivo -de modo que las prestaciones de Seguridad Social básicamente van precedidas de una financiación previa, mientras que las de asistencia social son independientes de esa misma contribución-. 3. La existencia de un derecho subjetivo perfecto, que se predica de las prestaciones de Seguridad Social, mientras que ese derecho se debilita o no existe en los supuestos de prestaciones de asistencia social.

De esta forma, se va configurando la asistencia social como un mecanismo residual, frente al carácter expansivo de la Seguridad Social, carácter residual, no obstante, que ha ido perdiendo en los últimos años, según se iban estableciendo verdaderos sistemas de asistencia social de carácter autonómico. Sin embargo, En la STC 239/2002, de 11 de diciembre, el Tribunal Constitucional, aún reconociendo la interdependencia entre Seguridad Social y asistencia social, señala que la última dispone en el ordenamiento español de un ámbito de actuación propio, en el que la Seguridad Social no puede entrar, negando, con ello, el carácter residual de la asistencia social, con lo que incrementa la dificultad de diferenciar la misma con la Seguridad Social, aun hoy no resuelta. Para mayor profundización acerca de este debate es de interés la consulta de PAnizo, J. A.: "La protección social de los discapacitados", en VV.AA., Curso sobre Protección Jurídica de las Personas con Discapacidad, Consejo General de la Abogacía Española, Fundación ONCE y CERMI. Madrid, 2006. 
destinatario de tales servicios, ya que en otros preceptos constitucionales se hace mención a la protección de grupos diferenciados, con necesidades específicas de protección - por ejemplo, los niños, los jóvenes, los discapacitados, los desempleados, etc.- 54 .

Pero, aunque la Constitución no delimita ni la asistencia social, ni los servicios sociales podemos concluir que, la realidad es que los mismos han experimentado un importante desarrollo, a través de las Comunidades Autónomas, como lo demuestran que se hayan articulado 17 Leyes de servicios sociales, a través de las cuales se ha procedido a una expansión de aquéllos -cierto es que sin la suficiente coordinación de los mismos- con la finalidad de que en cada región, comarca o municipio, según los casos, se trate de paliar las necesidades de carácter social más acuciantes.

\section{Seguridad Social}

El artículo 149.1.17 atribuye al Estado las competencias exclusivas en materia de legislación básica y régimen económico de la Seguridad Social, si bien esta atribución se efectúa sin perjuicio de la ejecución de sus servicios por las Comunidades Autónomas ${ }^{55}$.

Así, en cuanto a las competencias de las Comunidades Autónomas en materia de Seguridad Social, si profundizamos en el contenido del propio artículo 149.1.17 de la Constitución se desprende que las Comunidades Autónomas son las encargadas de la ejecución de los servicios de la Seguridad Social, en tanto no afecten al régimen económico del Sistema, de la gestión de los servicios transferidos, y de determinadas competencias normativas como la potestad legislativa cuando pueda ser conveniente para la aplicación de la legislación básica; las disposiciones reglamentarias en desarrollo de las disposiciones legales, que hayan sido dictadas por la Comunidad Autónoma en ejecución de la legislación básica; y, por último, la potestad reglamentaria de desarrollo de la legislación básica ${ }^{56}$.

${ }^{54}$ Vgr. Artículo 50 de la Constitución Española.

55 La doctrina constitucional incluye, en este caso, dentro del concepto de legislación básica no sólo la potestad legislativa sino también reglamentaria, en cuanto que lo básico ha de entenderse en un sentido material y no solo meramente formal. El Texto Refundido de la Ley General de la Seguridad Social se aprueba por el Real Decreto Legislativo 1/1994, de 20 de junio. Para profundizar en torno a esta cuestión puede consultarse el trabajo de Cabra De Luna, M. A.: "Dimensión y alcance de las políticas públicas sobre discapacidad en España: el reparto de papeles entre el Estado y las Comunidades Autónomas", en Estudios Revista del Ministerio de Trabajo y Asuntos Sociales, núm. 65, 2004, pp. 68 y ss.

${ }^{56}$ Respecto al régimen económico, el Tribunal Constitucional ha señalado (Sentencia 124/1989, de 7 de julio) que es competencia exclusiva del Estado "la gestión de los recursos 


\section{Salud}

En una análisis ya más superficial del reparto competencial en materia de salud, por alejarse ya del modelo de tratamiento jurídico de la discapacidad social que quiere configurar la Ley de Dependencia ${ }^{57}$. Podemos afirmar que el Estado tiene únicamente competencias sobre las bases y coordinación general de la sanidad, en definitiva sobre la determinación de mínimos que garanticen la equidad interterritorial (Art. 149.1.16. ${ }^{a}$ y $1 .{ }^{a} \mathrm{CE}$ ), correspondiendo el desarrollo de las bases y la gestión de la salud a las Comunidades Autónomas ${ }^{58}$.

Por su parte, la salud, entendida en sentido amplio, es un elemento de suma importancia para las personas en situación de dependencia, pues la ausencia de salud, las distintas patologías y deficiencias, interactuando con el factor social, son, en muchas ocasiones, el origen de la discapacidad, y en esa situación de objetiva desventaja de la que parten las personas con dependencia o discapacitadas para participar en el curso ordinario de la vida social, de ahí que se haya considerado preciso articular también, medidas de prevención adicionales a todas las medidas de integración social que se regulan en la norma analizada.

En esta línea, en la Ley de Dependencia y en los baremos que apruebe el Consejo territorial del Sistema se sientan las líneas básicas en cuanto al diagnóstico y valoración de la situación de dependencia, pero su desarrollo y gestión se ha establecido básicamente en el ámbito de las Comunidades Autónomas $^{59}$. Y en lo que respecta la rehabilitación comprende un conjunto

económicos y la administración del sistema, en aplicación de los principios de solidaridad financiera y caja única" con la finalidad de preservar la unidad del Sistema español de Seguridad Social y el mantenimiento de "un régimen público", es decir, único y unitario, (Art. 41 Constitución) que garantice la igualdad de todos los españoles en el ejercicio de todos los derechos y deberes en materia de Seguridad Social (Art. 149.1.1. ${ }^{\circ}$ Constitución). Todo ello, sin descartar la posibilidad de que las Comunidades Autónomas participen como entidades colaboradoras en la gestión siempre que se respete que los fondos recaudados fluyan automáticamente a la caja única centralizada de la Tesorería General de la Seguridad Social. Panizo, J. A.: "La protección social de los discapacitados", op. cit.

${ }^{57}$ Véase nota al pie n. ${ }^{\circ} 1$.

${ }^{58}$ El Tribunal Constitucional en el Fundamento 2. ${ }^{\circ}$ de la Sentencia 32/83, de 28 de abril ha señalado que "el Estado se ha reservado competencia exclusiva sobre sanidad exterior. Bases y coordinación general de la Sanidad. Legislación sobre productos farmacéuticos" (Art. 149.1.16). De esas tres materias, relacionadas entre sí como lo indica su colocación en un mismo punto del Art. 149.1, aunque estén separadas sintácticamente, añadiendo que por "bases y coordinación general de la sanidad" por exclusión respecto a la sanidad exterior, hay que entender que se refiere a la sanidad interior, esto es, a la sanidad dentro del territorio español.

59 Artículo 11. 1 a y b de la Ley de Dependencia. 
coherente y coordinado de medidas sanitarias, educativas, profesionales y de centros y servicios sociales, por lo que resulta, nuevamente, competencia fundamentalmente de las Comunidades Autónomas, y así han desarrollado la puesta en práctica del Sistema todas las Comunidades Autónomas ${ }^{60}$.

\section{2.c) Las competencias de los entes locales en la materia}

El tercero de los aspectos a tratar es el papel de los municipios en la materia de discapacidad. Como sabemos, los municipios son Estado y gozan de autonomía en la gestión de los intereses que le son propios y de personalidad jurídica plena. No obstante, en ningún momento la Constitución menciona cuáles son esas competencias propias de los municipios en concreto ${ }^{61}$.

Este punto de partida Constitucional nos debe llevar a la regulación genérica de los entes locales la Ley Reguladora de las Bases de Régimen Local de 2 de abril $1985^{62}$ y el Texto Refundido de las Disposiciones Legales Vigentes en materia de Régimen Local aprobado por el Real Decreto Legislativo 781/1986, 18 de abril ${ }^{63}$.

Esto es así a la vista de es la propia Constitución la que delimita el ámbito competencial que con carácter exclusivo corresponde al Estado y a las Comunidades Autónomas, y la que permite a las Comunidades Autónomas dotar de un contenido sustantivo a su propia autonomía a través de sus Estatutos, sin embargo, en lo que se refiere a los entes locales guarda silencio, y más allá del reconocimiento de su garantía institucional no se les asegura un contenido concreto ni un ámbito competencial determinado, sino que

${ }^{60}$ También legitimado por aplicación del Artículo 11 de la Ley de Dependencia.

${ }^{61}$ Artículos 137, 140 y 141 de la C.E.

${ }^{62}$ Esta Ley ha sufrido diversas reformas, pero debemos destacar como más importantes la realizada por la Ley 11/1999, de 21 de abril y la más reciente producida por la Ley 57/2003, de 16 de diciembre, de medidas para la modernización del gobierno local. Actualmente existe un Anteproyecto de la Ley Básica del Gobierno y la Administración Local. Su justificación radica en que la cuestión de las competencias locales no se presenta con los mismos componentes que cuando se elaboró la Ley en 1985. En realidad es un listado de servicios mínimos que hoy en día no responde ni a las necesidades de los ayuntamientos, ni a percepción que de la Administración Local hay que tener. Por ello se está planteando desde el Gobierno una reforma con la que se pretende concretar la autonomía local en relación con determinados aspectos de una materia o actividad, a través de un procedimiento simple de ámbito local que puede ser integrado en otro complejo de ámbito mayor.

${ }^{63}$ Además de la mencionada normativa básica en materia de Administración Local, también es preciso tener en cuenta otras normas básicas como es el Real Decreto Legislativo 2568/1986, de 28 de noviembre, por el que se aprueba el Reglamento de organización, funcionamiento y régimen jurídico de las entidades locales. 
remite la concreción de las competencias locales a la legislación estatal y autonómica, según el sistema constitucional de reparto de competencias entre éstos ${ }^{64}$.

Ahora bien, de un análisis de los preceptos legales citados hasta el momento podemos concluir que los municipios son actores principales en la materia que nos ocupa, pues en ellos podemos encontrar normas suficientes para situar a los municipios en uno de los principales agentes en materia de discapacidad y dependencia; por ejemplo, gran parte de las actuaciones que se deben acometer en materia de accesibilidad les corresponden a ellos, y además, son los que en último extremo tienen que cumplir y en algunos casos, desarrollar la ejecución las Leyes y Decretos provenientes de sus gobiernos autónomos.

Efectivamente, observando estas normas reguladoras del contenido y alcance de la autonomía local, en lo relativo a las competencias de los municipios, les corresponden por una parte, solo a los municipios con más de 20.000 habitantes, entre otras funciones, la prestación de servicios sociales, de promoción y de reinserción social, la ordenación, gestión, ejecución y disciplina urbanística, promoción y gestión de viviendas, pavimentación de las vías públicas urbanas y el transporte público de viajeros, en este último caso sólo representa una obligación para los municipios de más de 50.000 habitantes ${ }^{65}$. Pero en cualquier caso, todos los municipios españoles han

${ }^{64}$ En este sentido hay que recalcar aquí que la Constitución impone al Estado la tarea de atribuir a los Municipios y Provincias de forma general y permanente un ámbito competencial lo más preciso posible y ligado al interés local, de esta forma, los citados cuerpos legales - la Ley Reguladora de las Bases de Régimen Local de 2 de abril 1985 y el Texto Refundido de las Disposiciones Legales Vigentes en materia de Régimen Local aprobado por el Real Decreto Legislativo 781/1986, 18 de abril- son los instrumentos utilizados por el legislador estatal para ello. Así, estas normas actúan asimismo de límite a la capacidad de las Comunidades Autónomas de concretar el alcance del principio de autonomía de los entes locales. Por su parte, corresponde a las Comunidades Autónomas delimitar el contenido de la efectiva autonomía local de que van a gozar los municipios y provincias de su ámbito territorial y en materias de su exclusiva competencia. Este hecho resulta un dato relevante a la hora de concretar el grado de intervención que tiene el Estado y la Comunidades Autónomas en la determinación del alcance del principio de Autonomía Local, ya que si bien el Estado sólo va a garantizar un marco general determinado para hacer efectivo dicho principio, será la Comunidades Autónomas la que tengan un papel más relevante en dotar de efectividad en la práctica al mismo, ya que por la cercanía territorial con los municipios y provincias de la región y por el sistema de reparto de competencias entre el Estado y la Comunidad Autónoma, ésta está en una posición estratégica a la hora de determinar el alcance que va a tener dicho principio.

${ }^{65}$ La Ley 7/1985 de 2 de abril, Reguladora de las Bases de Régimen Local (LBRL) fija el régimen competencial de los Municipios en los arts. 25 y 26 y el de las Provincias en el art. 36. En relación a las materias citadas véase el artículo 26.1 a), b) y c) de la Ley Reguladora de las Bases de Régimen Local de 2 de abril 1985, 7/1985. Más en concreto, el articulo $25.2 \mathrm{k}$ ) que cita expresamente los servicios sociales y la promoción y reinserción social como materias sobre 
estado prestando hasta la actualidad este tipo de servicios bien a través de sistemas de gestión propios, o a través del apoyo que les ha prestado las Diputaciones provinciales y sus sistemas de gestión.

Todos estos aspectos mencionados están directamente relacionados con la materia que nos ocupa: el libre desarrollo de la personalidad y el ejercicio de los derechos de ciudadanía de las personas en situación de dependencia, pero especialmente tienen relación con la accesibilidad universal, mencionadas entre uno de los principios inspiradores de la Ley ${ }^{66}$. Y junto a estas competencias genéricas, es preciso tener en cuenta también que tanto la Administración Estatal como la Administración Autonómica, pueden delegar sus competencias en materia de servicios sociales en las entidades locales, tal y como se desprende de los arts. 8, 27 y 37 la Ley de Bases del Régimen Local (LBRL). Y así se ha hecho, algunos casos, como puede ser la sanidad, desde el momento en que la mayoría de la legislación sanitaria autonómica les atribuyera a ciertas competencias en materia de salud pública y de participación en la gestión de la atención primaria de salud.

En realidad, hay que tener presente que en la LBRL no se ofrece una lista determinada y formal de las competencias locales, sino que encontramos una remisión a leyes sectoriales. Y precisamente en la materia que nos ocupa, hay que acudir en más de una ocasión a la legislación sectorial del Estado y de la Comunidades Autónomas, que son las que, a las ultimas, tienen que garantizar la intervención municipal, mediante la atribución de las correspondientes potestades de planificación, normativa y de gestión.

Será la ley la que, en cada sector concreto, distribuirá las competencias entre los distintos Entes atendiendo al principio de descentralización y el principio de máxima proximidad de la gestión administrativa a los ciudadanos, reforzando el poder y gobierno local, de tal manera que se consiga ofrecer una

las que el municipio puede ejercer competencias. Y el artículo 26.1.c) concreta la obligatoriedad de su prestación a los municipios con población superior a más de 20.000 habitantes. Por su parte, en el art. 36 se atribuye indirectamente esta competencia a las provincias, que a través de las Diputaciones Provinciales, realizarán las siguientes funciones:

1. La coordinación de los servicios municipales entre sí para lograr la garantía integral y adecuada en la totalidad del territorio provincial.

2. La asistencia y la cooperación jurídica, económica y técnica a los Municipios, especialmente los de menor capacidad económica y de gestión.

3. La prestación de servicios de carácter supramunicipal y, en su caso, supracomarcal.

${ }^{66}$ En efecto, las diferentes normas autonómicas referidas a esta materia realizan menciones explicitas a los ayuntamientos en cuanto a las competencias que tiene que asumir en materia de urbanización, edificación o transporte, y lo que es más importante deben asumir el cumplimiento de las prescripciones legales que le vengan impuestas sobre esa materia por la normativa autonómica. 
solución al problema concreto o la prestación de servicio de una forma más cercana al ciudadano ${ }^{67}$.

Es por ello que, en mi opinión, es preciso garantizar un mínimo competencial de los entes locales en España a través de todas las normas estatales que regulen materias que afecten al interés local, para así garantizar una mejor gestión de los asuntos públicos. En este sentido, esta ley podría haber tenido más en cuenta el papel que nuestras entidades locales ya juegan en el Sistema para la Autonomía. Ya que sin competencias formalmente atribuidas, la financiación, sólo se asignará en función de las responsabilidades públicas que se entienden atribuidas a estas entidades territoriales. Sin embargo, sabemos que las actuaciones de los gobiernos locales van más allá aún de lo atribuido formalmente por las leyes, lo que determina la falta de capacidades de nuestros ayuntamientos de dar respuestas a las reivindicaciones de su ciudadanía, que en definitiva no entiende de repartos competenciales.

La respuesta a la necesidad de elevar el techo competencial de la autonomía local, viene dada básicamente en la aplicación de dos importantes principios jurídico-políticos. En primer lugar, por un lado, en una efectiva aplicación del principio de subsidiariedad recogido, entre otros textos jurídicos, en el artículo 4.3 de la Carta Europea de Autonomía Local, por el que se reconoce que "El ejercicio de las competencias públicas debe, de modo general, incumbir preferentemente a las autoridades más cercanas a los ciudadanos". Un principio que apuesta por descentralizar la gestión hasta la instancia territorial más cercana a los ciudadanos y no quedarse en el ámbito de la Comunidades Autónomas. Y de otro lado, relacionado con el principio de subsidiariedad, está la definición de lo que se debe entender por "interés local" como se reconoce en la carta magna. Que en definitiva sería todo aquello que afecte a los intereses generales de la comunidad y que, en todo caso, se actualizaría en función de las necesidades sociales del momento. Con una efectiva aplicación de ambos instrumentos la ampliación competencial de los entes locales sería una realidad que revertiría en la mejora de la calidad de vida de los ciudadanos y en la mejora de las prestaciones que se esperan del Estado de Bienestar.

En segundo lugar, la aplicación del principio de descentralización también puede ser una fórmula idónea para elevar las capacidades administrativas de

${ }^{67}$ Según este planteamiento, las Comunidades Autónomas promulgaron, por ejemplo, las respectivas Leyes de Servicios Sociales o de Acción Social en las que se contemplan los principios, las actuaciones y las prestaciones que han de realizarse para permitir el desarrollo e implantación de los Servicios Sociales en todo el territorio del Estado, y en concreto en los Municipios y Provincias. Con la aprobación de estas leyes, se establece un régimen público de Servicios Sociales y se garantiza la correspondiente coordinación de los recursos e iniciativas de carácter público y social. 
los entes locales, tal y como ya reconoce la Ley de Bases de Régimen Local en su artículo 2 cuando nos dice que "la legislación del Estado y la de las Comunidades Autónomas (...), deberá asegurar a los Municipios, las Provincias y las Islas su derecho a intervenir en cuantos asuntos afecten directamente al círculo de sus intereses, atribuyéndoles las competencias que proceda en atención a las características de la actividad pública de que se trate y a la capacidad de gestión de la entidad local, de conformidad con los principios de descentralización y de máxima proximidad de la gestión administrativa a los ciudadanos".

En este sentido sería necesario que las Comunidades Autónomas tengan en cuenta esas necesidades de defensa y de consecución de los que constituyen los intereses locales, y que deleguen y repartan responsabilidades en los entes locales, en todas aquellas competencias de su titularidad, cuando sean justificables en los requerimientos de una mayor eficacia y eficiencia en el desempeño de las funciones públicas.

\section{CONSIDERACIONES FINALES}

Y es que es preciso trabajar por evitar que la defensa de posiciones de poder y de mayores cuotas de competencia, como sucede en más de una ocasión, no terminen empañando las bondades que, desde políticos, juristas y médicos hasta asociaciones de discapacitados, de personas mayores, foros de familia, etc., han reconocido al articulado de esta norma, que incluso se ha llegado a calificar como "una de las Leyes más hermosas de nuestra democracia" ${ }^{68}$.

Algo de esto ya le está sucediendo a nuestra Ley de Dependencia. Tras casi un año y medio transcurridos desde su aprobación, el desarrollo de la Ley no avanza todo lo rápido que cabría esperar, y su aplicación es muy desigual en los distintos territorios de las Comunidades Autónomas. No todos los gobiernos con competencias expresamente atribuidas por la Ley la están aplicando con el mismo rigor, ni se están tomando el mismo interés en articular los mecanismos de cooperación interadministrativos necesarios para que los servicios y ayudas que reconoce la Ley lleguen a todos los ciudadanos por igual, residan en el territorio que residan ${ }^{69}$.

${ }^{68}$ Así lo puso de manifiesto Pedro Castro, presidente de la Federación Española de Municipios y Provincias (FEMP). En su intervención sobre el papel de los Gobiernos Locales en el Sistema para la Autonomía y Atención a la Dependencia en un curso de verano de la Universidad Internacional Menéndez Pelayo celebrado en Santander en agosto de 2008.

69 Según datos aportados por el balance del estado de aplicación de la Ley a 1 de septiembre de 2008, realizado por la Secretaria de Estado de Política Social, Andalucía es la Comunidad Autónoma donde se han producido un mayor número de solicitudes, más personas valoradas y más prestaciones reconocidas; a continuación figuran Cataluña, Galicia y la Comunidad Valenciana. 
Asimismo, a día de hoy aun existe una escasa participación de los ayuntamientos en la gestión del sistema de atención a las personas dependientes, de forma que la desigualdad en su aplicación se manifiesta, incluso, dentro de los diferentes municipios de una misma Comunidad Autónoma. Y cuando tienen reconocidas algunas cuotas de participación, estas se ejercen con una deficiente, casi inexistente, articulación de un sistema de colaboración interadministrativa que coadyuve a responder eficientemente a las demandas y solicitudes reclamadas por los beneficiarios ${ }^{70}$.

Efectivamente, no dejamos de oír cómo, junto con la necesidad imperiosa de articular un aumento de las dotaciones económicas para la correcta implantación de esta política, lo que constituye una reclamación histórica casi desde los inicios de la democracia; los ayuntamientos españoles también vienen reivindicando, desde su aprobación, una mayor responsabilidad en el Sistema de Autonomía y Atención a la Dependencia, o al menos, poder participar en la evaluación de las personas consideradas como dependientes a los efectos de las prestaciones y servicios que reconoce la Ley, lo que entienden, podría realizarse a través de los servicios sociales locales o municipales ya existentes, con un pequeño incremento de recursos humanos, centros y servicios en cada uno de los municipios ${ }^{71}$. Todo ello en la finalidad última de facilitar al máximo el acceso a las prestaciones reconocidas en la Ley y ello justificados en razones de celeridad y eficiencia en la concesión de las ayudas.

$Y$ es que en efecto, la red de servicios sociales de nuestro país se asienta, con una dilatada experiencia, en la Administración Local, bien a través de municipios, mancomunidades y provincias, y a través de sus Diputaciones, $\mathrm{o}$

70 Según la Encuesta de Discapacidad, Autonomía personal y situaciones de Dependencia (EDAD) realizada, el 4 de noviembre de 2008, por el INE. El 66,9\% de las personas con discapacidad recibe algún tipo de ayuda. Se ha investigado si las personas que presentan alguna discapacidad reciben algún tipo de ayuda, distinguiendo las ayudas técnicas de las que son prestadas por otras personas. Los resultados muestran que más de dos millones reciben asistencia, supervisión o cuidados personales y casi millón y medio ayudas técnicas. Sin embargo, más de un millón de personas afirman no recibir ningún tipo de ayuda para realizar las actividades para las que tienen discapacidad (el 26,6\% del colectivo).

${ }^{71}$ Muchas veces cuando las corporaciones locales tienen atribuidas la gestión del servicio que se reconoce en el ámbito del SAAD estos reclaman una mayor celeridad en la elaboración del Informe de Valoración por parte del órgano competente, que generalmente es un organismo adscrito a la Consejería de Bienestar de la correspondiente Comunidad Autónoma. Ya que la lentitud en esta fase del proceso implican reclamaciones ante los ayuntamientos, que se ven imposibilitados para dar una respuesta a los usuarios solicitantes de estos servicios, por tratarse de una acto que queda totalmente fuera de su ámbito competencial. De ahí que reclamen la participación en los informes de valoración, principalmente de aquellos que suponen la concesión de ayudas o servicio, cuya prestación queda eminentemente en el ámbito local como es la Teleasistencia o los servicios de atención domiciliaria. 
en los Consejos y Cabildos Insulares. De ahí que hayamos de reconocer que, pese al insuficiente desarrollo legislativo existente en este sentido, el ejercicio de la competencia de las prestaciones de los servicios sociales es una materia que ha de corresponder legítimamente a las entidades locales, esta es la garantía necesaria para que la calidad de las prestaciones sociales llegue a todos los ciudadanos con criterios de igualdad y eficacia, principios con los que debe responder toda Administración pública en el ejercicio de sus funciones.

Efectivamente, en el sistema configurado por nuestra ya tradicional Ley de servicios sociales, se atribuye a las Comunidades Autónomas los Servicios Sociales de Atención Especializada, a ellas les corresponde el nivel de intervención y actuación en razón de la mayor complejidad, la especialización y las características específicas de necesidad de la población a la que se dirigen sus actuaciones y recursos. Pero paralelamente, la titularidad de los Servicios Sociales de Atención Primaria, que constituyen el primer nivel de atención del Sistema Público de Servicios Sociales corresponde a los ayuntamientos ${ }^{72}$.

Es de su competencia ofrecer información, evaluación, diagnóstico y orientación en materia de servicios sociales; detectar, analizar y valorar las situaciones de necesidad; disponer de recursos y medios que faciliten la integración y la participación social; desarrollar actuaciones preventivas ante el riesgo o la exclusión social; intervenir en situaciones de riesgo y necesidad especial; prestar el servicio de orientación individual y familiar; atender la inserción laboral y educativa; gestionar (cuando no se tenga reconocida la situación de dependencia) las prestaciones del servicio de teleasistencia, servicio de ayuda a domicilio, servicio de comida a domicilio y colaborar y coordinarse con los Servicios de Atención Especializada.

Y todo esto, ha sido reconocido, de alguna manera, en la Ley de Dependencia, cuyo artículo 12 establece que las "Entidades Locales participarán en la gestión de los servicios de atención a los dependientes de acuerdo con la normativa de las Comunidades Autónomas" en un intento de consolidación y ampliación del sistema existente. Pero para la mayoría de los ayuntamientos españoles, no existe normativa que dé cumplimiento y desarrolle ese precepto, ni cuentan con mecanismos de participación o protocolo alguno en el que basarse para poder implicarse de forma más activa en el desarrollo de la Ley. Un requisito absolutamente necesario, para que las demandas de los ciudadanos puedan ser atendidas con la mayor eficiencia posible.

Porque es a los ayuntamientos donde llegan las demandas de los ciudadanos, porque es en ellos donde la ciudadanía ve la Administración más cercana y el nexo de unión más próximo al Estado o a la Comunidad Autó-

\footnotetext{
${ }^{72}$ Ley de Servicios Sociales 5/1996 de 18 de octubre.
} 
noma, y la mayoría de las ocasiones, nuestras corporaciones locales se encuentran sin servicios, ni recursos - económicos y humanos- adecuados a tales fines, atadas de pies y manos, y sin poder dar una respuesta satisfactoria a tales demandas.

Estas carencias terminan por empañar el avance en la consolidación del cuarto pilar del Estado del Bienestar. Pues lo que realmente ha pretendido la Ley es configurar un Sistema Público de Servicios Sociales en atención a las personas con discapacidad o en situación de dependencia en el que se integren un conjunto coordinado de recursos, programas, actividades, equipamientos, prestaciones de servicios y prestaciones económicas, encaminadas todas ellas a la atención, participación, promoción e incorporación social de toda la ciudadanía, así como a la prevención de las situaciones de desventaja o exclusión social.

Por ello se precisa hoy un marco conceptual y de gestión interadminstrativa que responda a las nuevas realidades derivadas del reconocimiento de un derecho subjetivo y de carácter universal, asumiendo el marco competencial en materia de Servicios Sociales y la obligación de prestarlos, centrándose especialmente en el trabajo preventivo y en la concreción de una red de centros y servicios de atención a los ciudadanos.

De ahí que insistamos en la necesidad de profundizar en la necesaria coordinación entre las administraciones. Porque si las Comunidades Autónomas tienen la competencia exclusiva en materia de servicios sociales y la Administración General del Estado tiene una responsabilidad directa en el desarrollo de la vigente de Ley de Dependencia a fin de garantizar la igualdad interterritorial, los Municipios tienen han de tener la competencia de la organización y gestión de la red que se configure en torno a esos servicios sociales reconocidos en el Sistema para la Autonomía y Atención a la Dependencia.

Y en un plano de colaboración leal y cooperación activa con la Administración Autonómica, tanto la red de Centros de atención al ciudadano con que ya cuentan los municipios, como fundamentalmente las Unidades Básicas de Acción Social, puede coincidir con el mapa disponible para otras prestaciones que se reconocen en la Ley, para posteriormente incorporarse en lo que será el Mapa de Servicios del SAAD.

Esto junto con la necesidad de llevar al efecto la necesaria ampliación del sistema a través del desarrollo de un nivel superior de protección, al otorgado por la Ley de Dependencia, tanto por parte de la legislación autonómica como mediante la suscripción de los respectivos convenios de colaboración con las entidades locales, son en la actualidad los retos a satisfacer por nuestras Administraciones públicas. 


\section{Estructura y características del Sistema para la Autonomía y la Atención a la Dependencia}


